\title{
Interplanetary survival probability of Aspergillus terreus spores under simulated solar vacuum ultraviolet irradiation.
}

\author{
E. Sarantopoulou ${ }^{\mathrm{a}}$, I. Gomoiu ${ }^{\mathrm{b}}$, Z. Kollia ${ }^{\mathrm{a}}$, A. C. Cefalas ${ }^{\mathrm{a}}$ \\ ${ }^{a}$ National Hellenic Research Foundation. Theoretical and Physical Chemistry \\ Institute, 48 Vassileos Constantinou Aven. Athens 11635, Greece. \\ ${ }^{\mathrm{b}}$ Institute of Biology, Romanian Academy, 296 Splaiul Independentei, Bucharest, \\ 060031, Romania
}

\begin{abstract}
This work is a part of ESA/EU SURE project aiming to quantify the survival probability of fungal spores in space under solar irradiation in the vacuum ultraviolet (VUV) (110-180 $\mathrm{nm}$ ) spectral region. The contribution and impact of VUV photons, vacuum, low temperature and their synergies, on the survival probability of Aspergillus terreus spores is measured at simulated space conditions on Earth. To simulate the solar VUV irradiation, the spores are irradiated with a continuous discharge VUV hydrogen photon source and a molecular fluorine laser, at low and high photon intensities at $10^{15}$ photon $\mathrm{m}^{-2} \mathrm{~s}^{-1}$ and $3.9 \times 10^{27}$ photons pulse $\mathrm{s}^{-1} \mathrm{~m}^{-2} \mathrm{~s}^{-1}$ respectively. The survival probability of spores is independent from the intensity and the fluence of photons, within certain limits, in agreement with previous studies. The spores are shielded from a thin carbon layer, which is formed quickly on the external surface of the proteinaceous membrane at higher photon intensities at the start of the VUV irradiation. Extrapolated the results in space conditions, for an interplanetary direct transfer orbit from Mars to Earth, the spores will be irradiated with $3.3 \times 10^{21}$ solar VUV photons $\mathrm{m}^{-2}$. This photon fluence is equivalent to the irradiation of spores on Earth with 54 laser pulses with an experimental $92 \%$ survival probability, disregarding the contribution of space vacuum and low temperature, or to continuous solar VUV irradiation for 38 days in space near the Earth with an extrapolated $\sim 61 \%$ survival probability. The experimental results indicate that the damage of spores is mainly from the dehydration stress in vacuum. The high survival probability after 4 days in vacuum $(\sim 34 \%)$, is due to the exudation of proteins on the external membrane, preventing thus further dehydration of spores. In addition, the survival probability is increasing to $(\sim 54 \%)$ at $10 \mathrm{~K}$ with $0.12 \mathrm{~K} / \mathrm{s}$ cooling and heating rate.
\end{abstract}

Key words: Life and interplanetary travel, VUV solar irradiation, Aspergillus, Panspermia.

Corresponding author: Evangelia Sarantopoulou. E-mail: esarant@eie.gr, Tel:+30210-7273839, Fax:+30210-7273842 


\section{Introduction}

The fungal spores are the most interesting species of the biological diversity as they have the highest survival probability when they are exposed at extreme conditions either in space or Earth. The spores and hyphae are able to germinate and grow under extreme environmental conditions, either on air, soil, ice or water (Talbot, 2001; Krumbein et al., 2004). They are particularly resistive at high or low temperature, pressure gradient and prolonged irradiation at different photon wavelengths (Rothschild and Mancinelli, 2001; Gorbushina, 2003). The number of fungal species is more than one million representing the most important phylogenetic member of the terrestrial ecosystem (May and Adams, 1997; Gorney, 2004). However regardless of been ideal paradigms of life at extreme conditions, only a relatively small number of cases has been studied (Fairen, et al., 2005; Amils, et al., 2007). Several investigations including theoretical molecular models were developed to describe the ability of spores to survive at extreme conditions (Setlow, 1995). The spores prevent the damage of their cellular content, by having thick cell walls and pigments, and above all, species with melanin in their external proteinacious membrane are extremely resistive to ultraviolet (UV) radiation (Kawamura, 1999; Gorbushina, 2003). In addition, they have the ability to repair and replace the damaged areas before reaching the critical values of ceasing their biological activity (Baker et al., 1992; Goldman et al., 2002).

The role of fungal spores in the panspermia debate is underlined from, (1) the possibility of a high survival probability in an interplanetary trip, (Arrhenius, 1908; Kern and Hock 1993; Hoyle and Wickramasinghe, 2000; Horneck et al., 2001; Mautner, 2002; Wickramasinghe, 2004; Wainwright et al., 2004), (2) the question of the origin of life on earth, (3) the possibility of the evolution of life on Mars and exoplanets, and (4) the possibility of life to survive a long cosmic trip under harsh conditions (Nussinov and Lysenko, 1983; Horneck, 1999; Hornevk, 2000; Wickramasinghe and Wickramasinghe, 2003; Nicholson et al., 2005). The recovery of Caenorhabditis elegans surviving the frictional heating of the re-entry of the space craft and the explosion (Szewczyk et al., 2006), contributes positively to the hypothesis of the interplanetary spread of life on Earth through meteors (Horneck et al., 2003). In addition, a single fungus and two bacteria were isolated from samples of air taken from the stratosphere (McLean et al., 2006). Furthermore Aspergillus niger and Clostridium mangenoti sp. have shown high survival probability under intense proton beam irradiation in vacuum, corresponding to 250 years of cosmic irradiation in solar space (Koike et al., 1992). In addition, it was shown that under extreme accelerations and pressure gradients of $100 \mathrm{GPa}$, there is still a finite survival probability depending on the type of organism (Burchell et al., 2004).

Ground simulation experiments of the space parameters, such as low pressure, radiation and temperature, spearhead reliable experimental approaches for predicting the survival probability of biological systems under extreme space conditions. Several successful attempts were made at various experimental platforms to simulate the interplanetary and the intergalactic conditions during an hypothetical cosmic trip of bio-matter and to assess the impact and the contribution of each one of the cosmic parameters on the survival probability of various virus arrays, pathogenic bacteria, and fungi (Horneck et al., 1971; Silverman et al., 1967; Koike et al., 1995; Nicholson et al., 2005).

While the response of biological systems in vacuum is straightforward, radiation exposure exhibits additional degrees of complexity (Weber and Greenberg 
1985; Lindberg and Horneck 1991; Fekete et al., 2004; Rontó et al., 2004). Indeed, the biological systems respond differently even at neighboring spectral regions of narrow spectral bands and the survival rate of spores exposed to vacuum ultraviolet VUV (110-180 $\mathrm{nm})$ or UV wavelengths $(180-400 \mathrm{~nm})$ under vacuum is wavelength and temperature dependent (Nicholson et al., 2000). In addition, simulations of the surface conditions of Mars or of the interstellar space indicate a small survival probability of unshielded spores exposed for long periods of time to solar UV radiation for wavelengths longer than $170 \mathrm{~nm}$ and space vacuum (Nicholson et al., 2000). The DNA strands in vacuum undergo various conformational changes, as the result of dehydration and stress, which are accelerated under UV radiation (Horneck, 1988; Horneck, 1999).

The experimental results evince that in the absence of adequate UV shielding, either by the thick proteinaceous membrane or by the fragments of interplanetary meteors, the bio-matter cannot survive and transported through space (Rettberg et al., 2002; Schuerger et al., 2005, Diaz and Schulze-Makuch, 2006). However various experimental results in space have shown that thick layers of spores, having the appropriate nutrients, could survive as long as 6 years (Horneck et al., 2001; Horneck et al. 2002) and certain types of fungi, not only can survive inside a space vehicle at low gravity conditions, but also indicate intense bioactivity causing biodegradation of spacecraft's materials (Kern and Hock, 1993; Zimmermann et al., 1994; Hahn and Hock 1999). For example, the fungal growth inside the MIR station in 1995 was from the descendants of fungi from 1988 and further investigations identified the presence of several microorganisms, which not only effected the optimal performance of the space crew, but also damaged the metals and the polymeric parts of the functional units, causing in some cases serious malfunction of the vehicle's systems (Novikova et al., 2006). It is evident therefore that additional data concerning long duration exposure of fungal spores under space conditions and at different wavelengths is needed in order to: 1) either sustain the hypothesis of interplanetary or interstellar transport of life or 2) find the optimum conditions for minimal growth and survival of fungi in space vehicles.

The majority of such investigations have been performed for UV wavelengths longer than $170 \mathrm{~nm}$, especially at $254 \mathrm{~nm}$, where the DNA absorbs the UV photons. On the other hand the VUV photons induce major photo-dissociation damages on the DNA molecules and its bases (Hieda, 1994; Cefalas, 2005; Sarantopoulou et al., 2006a). However, limited information is available in the literature on the effects of VUV and Extreme Ultraviolet (EUV, 10-110 $\mathrm{nm}$ ) radiation on the survival rate of microorganisms (Saffary et al., 2002; Koike et al., 1995; Heise et al., 2004; Cefalas et. al., 2001; Sarantopoulou et. al., 2006b). This is due to the experimental constrains at VUV wavelengths (Cefalas et al., 1993; Sarantopoulou et al., 1994). Taking into consideration that the solar VUV activity near the Earth is expressed with the photon intensity of $\sim 10^{14}-10^{15}$ photons $m^{-2} s^{-1}$ (Hardi, 2006; Woods et al., 1994), the need for further investigations on the viability of bio-matter when is exposed in VUV and EUV photons is self-evident.

Up to now the degradation of various space engineering organic materials by the Sun's VUV radiation between 115 and $200 \mathrm{~nm}$ has been studied by NASA (Dever et al., 2002) in space, and in ground simulated experiments (Sarantopoulou et al., 2009; Sarantopoulou et al., 2006 a,b; Cefalas, 2005; Kollia et al., 2004).

The physical mechanisms of destruction of bio-matter at VUV wavelengths are different than at longer UV wavelengths (Cefalas, 2005; Sarantopoulou et al., 2006a). In the VUV spectral region (7-11 eV) the absorption coefficient, and thus the 
penetration depth of the radiation in organic matter, is wavelength dependent and the density of the non-bound electronic states of organic matter from 7-11 eV is high. Therefore photo-dissociation of the organic matter is taking place and the dissociative rate depends on the molecular structure and the absorption coefficient of the organic matter (Cefalas, 2005). The VUV radiation affects only the external membrane and the surface proteins due to the small penetration depth of the VUV radiation. The VUV radiation completely dissociates the DNA bases of unprotected species, (Sarantopoulou et al., 2006a). At this spectral region one VUV photon breaks one chemical bond of the organic matter and the photo-fragments either are thrusting away from the irradiated area (Sarantopoulou et al., 2003 ) or they are attached on the external surface of the irradiated areas, building thus a thin carbon layer (Sarantopoulou et al., 2008). Therefore by exposing the organic matter at VUV wavelengths, either thin slices of matter are continuously removed from the bulk, or a thin carbon layer is building up on the external surface at the start of the irradiation. This process further prevents the photo-dissociation of the bulk material.

Recent experimental laboratory simulation of interplanetary VUV radiation on Deinococcus radiodurans indicated 2-7\% survival probability after $16 h$ (PaulinoLima et al., 2010). In addition it has been demonstrated that certain types of fungus, protected by multilayered proteinacious melanophore membranes, require higher lethal VUV radiation doses (fluence, intensity) (Greenberg et al., 1984; Sarantopoulou et al., 2006a), in comparison to the non-protected micro organisms (Wekhof et al., 2001).

The present work is part of ESA/EU project (SURE). It simulates extreme space conditions on ground to evaluate the survival probability of Aspergillus terreus spores in space under VUV irradiation. The spores are irradiated at different photon intensities with two different VUV photon sources. The first is a low intensity, longitudinal hydrogen discharge source tuned to emit $10^{15}$ photons $\mathrm{m}^{-2} \mathrm{~s}^{-1}$ and the second one is a high photon intensity pulsed discharged molecular fluorine laser that emits $3.9 \times 10^{27}$ photons pulse $e^{-1} \mathrm{~m}^{-2} \mathrm{~s}^{-1}$ at $157 \mathrm{~nm}$. Experiments are performed at the background pressure and temperature of $10^{-4}, 10^{5} \mathrm{~Pa}$, and 298 and $10 \mathrm{~K}$ respectively. The contribution of VUV photon fluence, vacuum pressure and temperature and their synergies on the viability of Aspergillus terreus is measured, evaluated or extrapolated. The relatively high survival probability of spores is described by a theoretical model that takes into account the activation of a protective mechanism by the spores, which prevents the dehydration in vacuum. Finally, the results are extrapolated to evaluate the contribution of VUV solar photons on the survival probability of Aspergillus terreus in space during a direct interplanetary trip starting from Mars and ending on Earth.

\section{Experimental setup and methodologies}

Fungi are randomly selected from a salted lake (Baia Baciului, Romania), where the environmental conditions are too extreme for other organisms to survive. The spores appear as aggregates of various shapes in the aqueous solution.

After their collection, they are grown on Petri dishes at $298 \mathrm{~K}$ and glucose-yeast extract-agar in salty water from the lake is used as the nutrient media. The aggregation is containing on the average $\sim 1.2 \times 10^{8}$ spores $\mathrm{m}^{-3}$.

The presence of water in the nutrient medium and the rough surface of cultures set up additional degrees of complexity on the optical microscopy analysis of the samples. The spores are deposited on the surface of silica wafers, used for 
microlithographic applications. The use of lithographic silica wafer substrates for biological cultures in vivo and bio applications (Douvas et al., 2005) has several advantages in comparison to plastic or glass substrates (Sarantopoulou et al., 2006 b). The surface roughness of the wafers is $\sim 0.1 \mathrm{~nm}$, giving the best surface adhesion and immobilization of spores whatsoever. Finally, silicon wafers are handled easier in the experimental configuration.

After drying, the samples are placed inside two different 316-stainless steel vacuum chambers at low and high pressure and temperature and at the same time they can be irradiated at VUV wavelengths. The spores are irradiated at low photon intensity in vacuum with a high voltage, continuously working, VUV hydrogen discharge source (Cefalas et al., 2000), tuned to emit the maximum amount of VUV photons at around $157 \mathrm{~nm}$ from the dipole transition between the $\mathrm{B}{ }^{1} \Pi^{+}{ }_{\mathrm{u}} \rightarrow \mathrm{X}^{1} \Sigma^{+} \mathrm{g}$ electronic states of the molecular hydrogen (Fig.1). The samples are placed $0.05 \mathrm{~m}$ away from the exit of the VUV source. The estimated photon intensity on the sample's surface is $\sim 10^{15}$ photons $\mathrm{m}^{-2} \mathrm{~s}^{-1}$ or $\sim 126 \mu \mathrm{W} \mathrm{m} \mathrm{m}^{-2}$, which exactly matches the solar VUV intensity in space near the Earth.

Additionally, the effect of low temperature and pressure on the survival probability of spores is measured by integrating the VUV hydrogen source to a closed cycle He cryostat at $10 \mathrm{~K}$, (Janis CTI, Cryogenics) (Fig. 2). The Aspergillus terreus samples are placed at the cryostat's cold finger for different time intervals up to $96 \mathrm{~h}$. The spores are exposed at low pressure and temperature in five stages. In the first stage, the rotary pump (Edwards E2M5) is adjusted to operate with initial and final pumping speed of $\beta(0) \sim 1.1 \times 10^{-3}$ and $\beta(\infty) \sim 0.57 \times 10^{-3} \mathrm{~m}^{3} \mathrm{~s}^{-1}$ respectively and the background pressure varies from $10^{5}$ to $1 \mathrm{~Pa}$ within $744 \mathrm{~s}$. During the second stage, a turbo-molecular pump (Edwards EXT 250) is operating at the average pumping rate of $7.4 \times 10^{-4} \mathrm{~Pa} \mathrm{~s}^{-1}$ for $1345 \mathrm{~s}$ from $1 \mathrm{~Pa}$ to the final pressure of $10^{-4} \mathrm{~Pa}$ with the pumping speed of $\sim 0.4 \mathrm{~m}^{3} \mathrm{~s}^{-1}$. In the third stage, the temperature decreases gradually to $10 \mathrm{~K}$ at the cooling rate of $0.12 \mathrm{~K} \mathrm{~s}^{-1}$ and, during the forth stage the spores are kept at $10 \mathrm{~K}$ for a certain period of time. During the fifth stage, the temperature first, and the pressure afterwards are increased gradually to $298 \mathrm{~K}$ and $10^{5}$ $P a$ respectively, tracking thus the reverse path of the stages one and two.

The survival probability of Aspergillus terreus spores at higher photon intensities is evaluated using a molecular fluorine laser at $157 \mathrm{~nm}$ (Cefalas et al., 1985) (Lamda Physic 250). The monolayer spores are irradiated either in vacuum $\left(10^{-4} \mathrm{~Pa}\right)$ (Fig. 3), or at higher pressure in nitrogen $\left(10^{5} \mathrm{~Pa}\right.$, Fig. 4). Both configurations were used previously to study the effects of VUV photons on engineering polymers (Sarantopoulou et al., 2009). They consist of the laser source, the focusing optics and the micro-precision translation stages, which are controlled by a computer. The spores are irradiated with 1-5.4 x 10 laser pulses. The fluence of the unfocused laser beam per pulse is $75 \mathrm{~J} \mathrm{~m}^{-2}$, and the pulse duration at full width at half maximum (FWHM) is $15 \mathrm{~ns}$ and the repetition rate is $15 \mathrm{~Hz}$.

In order to attain the same conditions of deposition and dehydration of spores in one hand, and to facilitate the comparison between the irradiated and the nonirradiated areas on the other, a part of the silica wafer area is masked against the VUV radiation prior its insertion in the vacuum chamber

The spores are examined with an optical metallographic microscope (Leica DMRX) and an atomic force microscope (AFM) prior and after the VUV irradiation, for identifying the morphological changes of the single spores and their aggregations. The AFM imaging is the most suitable methodology to investigate the morphology of the biological surfaces and to probe the molecular interactions on the surface of 
spores in vivo during germination or irradiation (Zhao et al., 2005; Dufrene et al., 1999; Zhao et al., 2005; van der Aa, et al., 2002; Ma et al., 2005; Dufrene et al., 2002; Sarantopoulou et al. 2006b). Ambient AFM imaging of the surfaces of both irradiated and non-irradiated spores is carried out with the "Quesant -Qscope 250".

The AFM is equipped with a 40- $\mu m$ Dual PZT scanner. The imaging is carried out with the NSC16 silicon cantilever. High-resolution imaging of the surfaces of spores is obtained at different scanning areas at the maximum scanning rate of $3 \mathrm{~Hz}$ and with image resolution of 600 pixels $x 600$ pixels. The AFM images are obtained in the intermittent contact mode. The acoustic and the thermal screening of the microscope successfully unveil the image details.

The survival probability of spores is calculated at different conditions. The survival probability $\left(N / N_{0}\right)$ is calculated with the optical microscope by comparing the number $N$ of undamaged spores from a great number of monolayer aggregations in a standard area of $100 \mu m \times 100 \mu m$ to the total number $N_{0}$ of spores at the same area. By exposing the spores at extreme experimental conditions, they are suffering deformation, discoloration, shrinking, partial mechanical damage and disintegration due to the hydration stress in vacuum. The exploded spores are count as the damaged population. Deformation, elongation or shrinking without major damages, discoloration and minor mechanical damages are count as the surviving population. All spores appear with major or minor defects when they exposed in vacuum.

After exposure, the spores are extracted from the silica wafer with sterile distilled water. The dilution of spores is spread on the nutrient agar plates. The plates are incubated for $24 h$ at room temperature. The final criterion of the viability of the population is the indication of growth of population for $24 h$ in a nutrient medium following the exposure at the extreme experimental conditions.

\section{Results}

The rigid external membrane of the fungal spores has a stratified configuration and consists of chitinous micro-fibrils embedded in a matrix of small polysaccharides, proteins, lipids, inorganic salts, and pigments (Claverie-Martin et al., 1988). The external membrane of the fungal spores has a dynamic elastic structure, which provides sufficient stability to withstand the osmotic and the hydration stresses, and at the same time it has the adequate plasticity to allow the growth of spores, and the effective interaction with their environment. The osmotic stress can be as high as (1540) $\times 10^{5} \mathrm{~Pa}$ (Davis et al., 2000). The elastic modulus of the external membrane is 6.6 - $22 \mathrm{GPa}$ (Zhao et al., 2005). The change in the synthesis and the structure of the external membrane and the presence of defects adjust the growth and the morphology of the fungal colonies. Consequently, any disruption of the functionality of the plasma membrane will cease the biological activity of the cell.

The Aspergillus terreus spores are deposited on the silica wafer prior to VUV irradiation in vacuum and low temperature. The spores appear in the optical microscope as rough-walled brown structures (Fig. 5a) and some of them are joined together to form chains. A typical AFM image of an individual spore is shown in (Fig. $5 b)$. The spores have prolate ellipsoid shape with granular star-like structures 100-200 $\mathrm{nm}$ long and they have rough vesicle structures with single and uniform layers, or they have smother conidiophore ellipsoid structures (Fig. 6a-b). High resolution imaging of the surface reveals morphological aspects of $20 \mathrm{~nm}$ wide rodlet structure on granular domains $100 \mathrm{~nm}$ long (Fig. 7). The chemical analysis indicated that the outlet rodlet 
layers are essentially made of proteins (Horikoshi and Iida 1964; Ellis et al., 1978; Cole et al., 1979; Dute et al. 1989; Heise et al., 2004; Romano et al. 2004). The proteins are assembled in parallel structures to form fascicles interlaced at different orientations (Fig. 7). The rodlet layer is significantly softer than the underlying part of the membrane indicating intensive biological activity (Zhao et al., 2005).

\subsection{Spores at $10^{-4} \mathrm{~Pa}$ and $298 \mathrm{~K}$.}

Dried suspensions of spores and hyphae are immobilized on silica wafers and then they are exposed in vacuum at $10^{-4} \mathrm{~Pa}$. The survival probability of spores at different time intervals, temperature and irradiation conditions is indicated in Fig. 8 and Table 1. The damaged spores are the $66 \%$ of the initial population. A substantial part of the population is surviving the initial stress at low pumping speed. Its viability is constantly reduced but is stabilizing after $24 h$ and remains constant afterwards (34\%) within the time scale of the experiment $(96 h)$.

Part of the population is suffering mechanical damages either by elongation along the major-semi axes and the appearance of deep and shallow structures or by missing various parts of the original structure (Fig. 9). The exposed population in vacuum exhibits excessive rod-like self-organized periodic structures, which are absent in the non-exposed population (Fig. 9-A). The periodic structures indicate excessive biological activity by exuviating proteins on the surface to avoid dehydration. Besides AFM imaging, the release of proteins is identified with the AFM tip from the colloid response of the surface. The rod-like structure appears on the non-dehydrated part of the spore, while is absent on the dehydrated one (Fig. 9-B). Fragmentation of the cell walls and subsequent release of the cytoplasm is also identified, while the contour of the cell walls remains attached on the substrate (Fig. 10). Parts of the populated areas are empty from the cellular content, indicating thus explosion of spores from the increment of the hydration pressure in the cytoplasm. The images of the exposed and non-exposed parts of the population point out to considerable macroscopic differences (Fig. 11.a, b). The fracture of the cell walls in vacuum is due to the dehydration and the subsequent increment of the hydration stress, in agreement with the early results (Brueschke et al., 1961).

\subsection{Spores at $10^{-4} \mathrm{~Pa}$ and $10 \mathrm{~K}$.}

The survival probability at low temperatures, besides the genus, depends on the cooling and the warming rates (Mazur, 1961; Mazur, 1984) and the type of solute molecules in the cell.

The optical and the AFM images at low pressure and temperature identify missing of aggregates, movement of individual spores, dehydration and remnants of exploded spores. The damaged spores appear to be empty of their cellular content (Fig. 12a). The image of a spore (A) and the trace of an exploded one (B) are shown in (Fig. 12b). The survival probability of spores after $24 \mathrm{~h}$ at $10^{-4} \mathrm{~Pa}$ and $10 \mathrm{~K}$ is $54 \%$, considerable higher than at $298 K$ (Fig. 8, Table1). Below $273 K$, the dehydration rate is gradually decreasing and prevents the explosion of the cell from the pressure gradient. The ratio of the vapour pressure of the water at 100 and $298 \mathrm{~K}$ is $\sim 10^{-6}$. By extrapolating the Goff-Gratch equation (Goff and Gratch, 1946) at $10 \mathrm{~K}$, the water's vapour pressure is practically zero. The critical temperature for biological activity is between 258 and $213 \mathrm{~K}$. At temperatures below $77 \mathrm{~K}$, fungi in vivo can be stored for 
long periods of time (years) and the effects of the icy conditions can be eliminated as the water vitrifies (Bosmans, 1974; Schipper et al., 1976).

Finally, taking into consideration that spores are cooled down to $10 \mathrm{~K}$ within $2316 \mathrm{~s}$, the relatively high survival probability of spores at low temperature $(54 \pm 12 \%)$, is attributed to the low dehydration below $213 \mathrm{~K}$. The time lapse between the room temperature and the critical one $(213 \mathrm{~K})$ is $708 \mathrm{~s}$. It is argued that the main damage of spores will take place before the population attains its critical temperature.

3.3. Aspergillus terreus irradiated with low intensity VUV photons at $10^{-4} \mathrm{~Pa}, 298$, $10 \mathrm{~K}$.

The survival probability of spores following $24 h$ of irradiation with the hydrogen source at $10^{-4} \mathrm{~Pa}$ and $298 \mathrm{~K}$ is $28 \pm 7 \%$ and remains constant for $96 \mathrm{~h}$ (Table 1 ). The survival probability of the irradiated samples after $24 h$ at $10 \mathrm{~K}$ is $54 \pm 9 \%$, indicating that the spores are damaged well before freezing. The damaged cell walls appear to have various shape and size holes on the surface (Fig.13-A) and part of the cellular content 100-200 $\mathrm{nm}$ wide, is spread around, (Fig.13-B, Fig 14). The photodissociation of the external membrane partially assists the cell's explosion by reducing its strength as below a certain thickness the membrane explodes. The survival probability at $10 \mathrm{~K}$ is considerably higher than at $298 \mathrm{~K}$, either in vacuum or under the combined action of vacuum and VUV photons, due to vitrification that prevents damage. Furthermore, the survival probability of spores at different exposing times and fluence $F_{S}$, for $24 h$ (Table 2) and up to $96 h$ at $10^{5} \mathrm{~Pa}$ and $298 \mathrm{~K}$ is $\sim 96 \%$.

\subsection{Spores irradiated with VUV laser photons at $10^{5} \mathrm{~Pa}$ and $298 \mathrm{~K}$.}

The optical path of the beam is filled with $\mathrm{N}_{2}$ gas at $10^{5} \mathrm{~Pa}$. The photon intensity is $3.9 \times 10^{27}$ photons pulse $e^{-1} \mathrm{~m}^{2} \mathrm{~s}^{-1} \quad\left(75 \mathrm{~J} \mathrm{~m}^{-2}, \quad 5.9 \times 10^{19}\right.$ photons puls $\left.\mathrm{s}^{-1} \mathrm{~m}^{-2}\right)$. The survival probability following irradiation with $5.4 \times \quad \times \quad 10^{4}$ pulses ( $F_{L}=3.18 \times 10^{24}$ photons $m^{-2}$ ) is $85 \pm 14 \%$. The growing rate of the surviving population in the nutrient environment is $2 \mathrm{~mm} /$ day (Table 2). The survival probability with only one focused laser pulse $\left(4.7 \times 10^{5} \mathrm{~J} \mathrm{~m}^{-2}\right)$ is $0 \%$. The AFM images indicate that the spores are destroyed by thermal ablation in the case of focused laser beam (Cefalas et al., 2001; Kollia et al., 2004). The survival probability is rather independent over a wide range of photon fluence $\left(10^{17}-10^{24}\right)$ photons $\mathrm{m}^{-2}$.

\subsection{Spores irradiated with VUV laser photons at $10^{-4} \mathrm{~Pa}$ and $298 \mathrm{~K}$.}

The survival probability of spores following laser irradiation in vacuum at $10^{-4}$ $\mathrm{Pa}, 298 \mathrm{~K}$ at different photon fluence is shown in Table 3.

The change of morphology of population following irradiation with a large number of pulses is noticeable. It includes mechanical damage of surface, discoloration, splitting, bursting of walls, spread of cellular contents, and shrinking. The AFM images of the damaged spores reveal the appearance of holes on the external surface, (Fig.15, 16). The combination of low external pressure and VUV irradiation acts negatively on the survival probability of spores. The Aspergillus terreus exposed to high intensity VUV radiation in vacuum have almost twice lesser survival probability, compared to the irradiation in nitrogen at $10^{5} \mathrm{~Pa}$ (Fig.17). 
The survival probability of spores at different laser fluence $F_{L}$, at $10^{5} \mathrm{~Pa}$ and $298 \mathrm{~K}$ is $80-100 \pm 16 \%$ (Table 2), while at $10^{-4} \mathrm{~Pa}$ and $298 \mathrm{~K}$, for $24 \mathrm{~h}$ continuous irradiation with the low intensity photon source the survival probability is $28 \%$ (Table $1,3)$. The results indicate that the survival probability is independent on the photon fluence at $10^{5} \mathrm{~Pa}$ and demonstrate the catastrophic effect of the vacuum on the biological functionality of spores.

\section{Discussion}

\subsection{Spores in vacuum at $10^{-4} \mathrm{~Pa}$ and $298 \mathrm{~K}$.}

Aspergillus sp. microscopic images demonstrate hyphae and conidiophore microscopic features. The last originates from the basal foot cell located on the supporting hyphae and terminating in a vesicle at the apex. The colour and the morphology of the conidiophores structures, covering partially or entirely the vesicle are the two main characteristics to identify the different species. The average size of spores, which usually form radial chains, is between 2 and $5 \mu \mathrm{m}$.

The survival probability of Aspergillus terreus in vacuum is related to the ability of the membrane to absorb the hydration stress from dehydration in vacuum. At low and high pumping speed, $10 \%-60 \%$ and $90-85 \%$ respectively of the water content of the cell evaporates respectively (Yarwood, 1950; Bosmans, 1974).

Various theoretical models were developed to describe dehydration (Bryant and Wolfe, 1992; Wolfe and Bryant, 1999; Wolfe and Bryant 2001). The low background pressure $P_{e}(t)$, equation $A 3$, causes unfolding and non-functionality of proteins and close packing of the hydrocarbon chains of phospholipids. The different layers of the membrane are $0.5 \mathrm{~nm}$ apart on the average. At this distance, all hydrophilic surfaces experience a strong repulsion (hydration force) in water solutions. By removing the inter-membrane water, the thickness of the intermembrane layers reduced and the hydration force and pressure are increasing together with the osmotic pressure of the cell. The hydration force decreases exponentially with the separation length $y(t)$, equation $A 7$. The membrane does a considerable amount of work to compensate the strong repulsion by reducing the area of the intermembrane layers, compressing the various layers of the membrane and at the same time is keeping the water content at a high level. The crucial point for the survival of spores is to maintain the water surface density $N(t)$ at time $t$, equations $A 4, A 6$, well above a critical value, stopping thus dehydration before the hydration stress exceeds the fracture yield of the membrane. A theoretical model based on the assumption that the survival probability is proportional to the relative concentration of water remaining in the spore and taking into consideration the pressure pumping rate $\alpha$ and the response time of the spore to stop dehydration $\frac{1}{\gamma}$, is given in Appendix A. By fitting the experimental results to equation $A 5$, it is found that the protective biological functionality is activated in vacuum within the time scale $t=\frac{1}{\gamma} \approx 434-666 \mathrm{~s}$, (Table 4). When the pumping speed rate $B_{1}$ or the rate of change of the pumping speed $\alpha$ are greater than the response rate of spore $\gamma\left(B_{1}, \alpha \succ \gamma\right)$, the spores are dehydrated ( 
$N(t \rightarrow \infty) \rightarrow 0 \quad$, equation A6. In the opposite situation where $B_{1}, \alpha \prec \gamma$, then $N(t \rightarrow \infty) \approx N(t=0) \quad$ and dehydration is prevented.

Furthermore, the overall pressure stress $\Delta P(t)$, exerted on the membrane in vacuum, increases exponentially with decreasing surface density of the water, equations $A 11$, ( Fig. 18). In the case of fast pumping rate (560 $\mathrm{Pa} \mathrm{s} \mathrm{s}^{-1}$ ), the dehydration rate is high and the surface density of water goes to zero within $\sim 2500 \mathrm{~s}$. At the same time the hydration pressure increases exponentially (Fig.18). The hydration pressure increases prior to the activation of the shielding functionality, in agreement with the experimental results of zero survival probability. In this case the silicon wafer is emptied from spores due to their violent explosion during the first few seconds in vacuum.

At low pumping speed, the water density in the long time limit is different than zero. In this case the dehydration parameter is small (e.g. $x=0.1$ ), equation $A 6$, and the majority of the initial water content (e.g. 90\%) remains in the spore. The hydration stress in this case is constantly increasing and after some time $\left(10^{4} s\right)$ is saturated attaining its maximum value (Fig.18). Taking into consideration that the survival probability is proportional to the relative concentration of water remaining in the cell, under the current experimental conditions, $31 \%$ of the initial water content is expected to remain in the spore in the worst case, in agreement with previous results (Brueschke et al., 1961).

In the case of multilayer colonies of spores, the under layer population is further protected by the exterior population as it suffers limited dehydration.

Furthermore the specific biological functionality adjusts the distribution of the internal stress from the re-folding of proteins, and at the same time it attempts to maintain the integrity of the membrane, the translation of the ions and the stability of the macromolecules (Mert and Dizby, 1977).

Due to the hydration stress, the spores are plastically deformed in vacuum along the semi axes by $6 \% \pm 2 \%$ on the average (Figs $5,9,10,12-16)$. The limits of the hydration stress can be estimated from equation $A 15, \Delta P(t \rightarrow \infty)=(0.1-2.5) E$, where $E$ is the Young modulus of the membrane.

As a rule of thump, the spores can survive when the hydration stress in vacuum is comparable to the Young modulus of the external membrane, provided that the pumping speed is small.

\subsection{Spores at $10^{-4} \mathrm{~Pa}$ and $10 \mathrm{~K}$.}

At low temperatures intracellular ice crystallization is lethal for the cells. When ice is formed in aquatic solutions, most solutes are separated from the ice in a concentrated unfrozen solution. High concentration of salts affects the ionic interactions, including those that stabilize the state of enzymes. The unfolding and denaturation of enzymes is often irreversible. Icing can be prevented by supercooling, freezing point depression, dehydration and vitrification. Dehydration raises the hydration and the osmotic stresses of the intracellular solution, which lowers the freeing temperature and promotes vitrification. The critical parameters are the cooling and the warming rates. Various equations were developed to describe the kinetics of the water loss and to predict the odds of intracellular freezing as a function of cooling rate (Mazur, 1984). At relatively low rates of cooling, the cells are loosing their water and eventually they shrink, but most cells do not in fact become highly distorted during 
the slow freezing phase. At higher cooling rates, depending on the cell's permeability, the water cannot escape quickly enough from the cell and super cooling of the cytoplasm is taking place. For aqueous solutions of typical cryoprotectans, the cooling rate of 0.1-10 $\mathrm{K} \mathrm{s}^{-1}$ is sufficient to achieve vitrification. Besides the importance of cooling rate, the warming rate plays an additional critical role for the survival of spores, (Mazur, 1960). Although low cooling rate is lethal, rapid warming of cooled samples $\left(10 \mathrm{~K} \mathrm{~S}^{-1}\right)$, could compensate the lethal effects to a certain degree. The overall response of the cells to low temperature depends critically on the structure of the specific cell, the nucleation temperature, the permeability of the membrane and the ability of the cell to withstand the dehydration and freezing phases as is demonstrated by the survival of certain microbial organisms in Antarctica for million of years (Wynn-Williams and Edwards, 2000; Onofri et al., 2004; Wickeramasinghe, 2004), while Aspergillus terreus spores can be maintained in the laboratory for 18 years by lyophilization (Ellis and Roberson, 1968).

The survival probability of spores at $10^{-4} \mathrm{~Pa}$ and $10 \mathrm{~K}$ is increasing to $54 \%$, in agreement with the $48 \%$ survival probability of Aspergillus niger reported previously by (Koike et al., 1992) for 24 hours of exposure at $5 \times 10^{-4} \mathrm{~Pa}$ and $77 \mathrm{~K}$. Cooling at 10 $K$, is improving a great deal the survival probability of Aspergillus terreus monolayers for the current experimental cooling and warming rates. Taking into consideration the data of Fig. 8, it is evident that deep freezing of spores is increasing their survival probability by preventing internal explosion and dehydration in vacuum. The major contribution to the mortality of spores is from exposure at low pressure during the first $30 \mathrm{~min}$, before the freezing of the cellular content. Higher survival rates of the order of $90 \%$ have been observed at $10^{-6} \mathrm{~Pa}$ and $150 \mathrm{~K}$ and in all cases the water of spores is in icy phase (Tuleta et al., 2005). During the dehydration state the osmotic pressure of the cytoplasm is increasing, the freezing temperature is lowering and the icy state is inhibited. The dehydrated cells, near the equilibrium and before the icy temperature, have zero probability to undergo intracellular freezing (Mazur, 1984). This intermediate thermodynamic state is causing extensive cell damage, but it can be avoided at low cooling rate, providing that the cells will survive the initial shock from the pressure gradient (Elis et al., 1968).

\subsection{Spores irradiated with low intensity VUV photons at $10^{-4} \mathrm{~Pa}, 298 \mathrm{~K}, 10 \mathrm{~K}$.}

Previous investigations of the effect of UV radiation on fungal spores (Leatch, 1971; Rotem et al., 1985; Boyd-Wilson, 1998) indicated that differences exist between the genera when it is exposure at short UV radiation, especially for the melanophore ones. Melanin is accumulating in the cell walls. Recent results demonstrate that melanin confers UV/VUV tolerance and resistance when is densely deposited on the conidial or hyphae surface (Rotem et al., 1985). It is therefore expected that among fungi, hyaline appearance, e.g. Basipetospora halophila is more sensitive in UV-VUV exposure in comparison to the melanin bearing filamentous fungi such as Aspergillus sp., Cladosporium sp., Ulocladium sp., etc.

The survival probability of fungal spores exposed to UV/VUV radiation mainly depends on the effect it has on the external carbonaceous protective membrane and it is strongly depended on the penetration depth of the radiation in the cell. The higher the penetration depth, the lesser is the survival probability. While at $193 \mathrm{~nm}$ the radiation penetrates few microns deep, the penetration depth at $157 \mathrm{~nm}$ is 10-100 times lesser than at $193 \mathrm{~nm}$. Therefore the damage from VUV radiation is expected to occur mainly on the external part of the membrane. On the other hand, the thickness 
of the external membrane depends on several parameters such as the fungal species, the cell type, the growth conditions including the nutrient and the maturity of the species. As an example, the hyphen walls of Aspergillus nidulans varies between 44 and $48 \mathrm{~nm}$ depending on the grown temperature (Kaminskyj et al., 2004) the vesicle wall of the Aspergillus clavatus is $500 \mathrm{~nm}$ thick (Hanlin, 1976), while in the young conidiophore of Aspergillus the primary wall does not exceed $500 \mathrm{~nm}$ (Castle, 1945). In addition, transmission electron microscopy revealed that the conidial wall of the wild-type Aspergillus nidulans strain was composed of three layers an irregular, electron-dense outer layer varying from $40 \mathrm{~nm}$ to $190 \mathrm{~nm}$ in thickness; an electrontranslucent middle layer 40-70 $\mathrm{nm}$ thick; and a thin, electron-dense inner layer 10-15 $\mathrm{nm}$ thick, which is intimately associated with the plasma membrane (Martin et al., 1988).

Several early, ground based, studies investigated the interaction of filamentous fungi with UV light. Genetic changes induced by UV light were reported for Aspergilus nidulans, Aspergillus terreus and Aspergillus sp. (Swanson, 1952; Mishra and Nandi, 1959; Jansen, 1964; Käfer and Chen, 1964; Kwiatkowski and Grad, 1965; Calvori and Morpugo, 1966). High survival probability of Aspergillus niger (83\%) in vacuum under UV irradiation for 7 days was reported and compared to the low survival probability of Bacillus megaterium (0.002 \%), B. subtilis var. niger $(0.001 \%)$, and $B$. sterothermophilus $(0.02 \%)$, (Silverman et al., 1966). The combined treatment with ethylenimine and UV light yielded enhanced Aspergillus niger mutans (Imshenetskii and Kuzyurina, 1966). Additional effects of UV light on the metabolic action of filamentous fungi were investigated too. The UV induced Aspergillus terreus mutants at $254 \mathrm{~nm}$, lessens its survival to $5 \%$ after $2 h$ of exposure, while the synergy of $\mathrm{H}_{2} \mathrm{O}$ and UV light accelerated the mortality (Wix et al., 1959 ; Jakubowska et al., 1960; Grebeshova, 1964; Ishiie, 1966; Matsushima and Simada, 1967; Chang et al., 1968). At the same time filamentous fungi exposed to spaceflight stress including UV exposure (Glembotskiy et al., 1962; Volz and Dublin, 1973; Dublin and Volz, 1973; Horneck et al., 1974; Horneck et al., 1988) indicated that UV photons longer than 200 $\mathrm{nm}$ are responsible for the high mortality of microorganisms.

Despite the small penetration depth of the VUV radiation, the damage of the protective external membrane of fungus under VUV irradiation is severe compared to longer UV wavelengths because one VUV photon breaks one chemical bond of the membrane molecules. Indeed, for all the organic molecules with aliphatic or aromatic structure the density of the dissociative excited electronic states between $\sim 10-7.2 \mathrm{eV}$ is high. The illumination at VUV wavelengths has a higher probability of breaking the chemical bonds commonly encountered in organic molecules and causing thus outgassing and photochemical ablation in comparison to longer wavelengths.

During the time of exposure to UV/VUV photons, two kinds of processes are induced on the polysaccharide chitin and cellulose membrane of fungi: the first being excitation followed by relaxation to the ground electronic state of the molecules, and the second being excitation followed by molecular disintegration. In the first process, which exclusively accompanies illumination at longer wavelengths, the electronic excitations relax by internal energy conversion to the vibration excitations of the molecules. In the second process, the photon energy is expended in breaking the chemical bonds, and forming thus molecules with smaller number of atoms. The excess amount of energy is converted into translation energy of the photo-fragments (Cefalas, 2005). It is therefore expected at VUV wavelengths, the protective membrane of spores and hyphae to be photo-dissociated and eventually to be destroyed. 
Following the experimental procedure, the fungi are irradiated with low VUV photon fluence in vacuum at room temperature. Significant morphological changes are identified after $24 h$ of irradiation, the spores irradiated with $8.6 \times 10^{19}$ photons $m^{-2}$ (Table 3 ) and their survival probability is reduced to $28 \%$ from $33 \%$ without irradiation (Table 1). The survival probability of Aspergillus terreus lessens only by $5 \%$ after $24 h$ of irradiation at low VUV photon fluence . This can be the result of formation of a carbon rich layer during the VUV irradiation, which covers up the surface of the fungi and eventually absorbs or reflects the VUV photons preventing thus the lethal VUV photons to reach the cytoplasm. A carbon rich layer was formed followed VUV irradiation of thin polymeric membranes and the formation of the carbonaceous thin films following VUV irradiation modifies the hydrophilicity and the hardness of the surfaces (Sarantopoulou et al., 2008; Sarantopoulou et al., 2009).

The flux of solar VUV photons at satellite orbits near the Earth, during the normal Sun activity, in the spectral region from $100-170 \mathrm{~nm}$, is $\sim 10^{15}$ photons $\mathrm{m}^{-2} \mathrm{~s}^{-1}$ $\left(1.26 \mathrm{~mW} \mathrm{~m}^{-2}\right)$, which is equivalent to the flux of $8.6 \times 10^{19}$ photons $\mathrm{m}^{-2}$ emitted at $24 h$ (Table 3). The survival probability of the irradiated samples in vacuum at 298 and $10 \mathrm{~K}$ is $28 \%$ and $58 \%$ respectively (Table 1). These values are comparable to the survival probability in vacuum for the non-irradiated samples $(33 \%$ and $52 \%$ respectively). The experimental results indicate that the VUV photons, from the low intensity VUV source, have a minor effect on the survival probability of spores after $24 h$ of irradiation. This result is in agreement with previous results (Saffary et al., 2002).

\subsection{Spores irradiated with high intensity VUV laser photons at $10^{5}, 10^{-4} \mathrm{~Pa}$ and 298} $K$.

The high intensity VUV laser photons induce mechanical damage on the nanometer scale on the fungal membrane. Since the dynamics of the fungal cell wall is closely coordinated to the cell's growth and division, its predominant functionality is to control the internal pressure of the cell and any disruption of the cell's wall structure leads to osmotic instability and, ultimately to lysis of the fungal cell. The power density of the laser is sufficient to ablate selected regions of the cell wall up to a certain depth. Shrinkage in the thickness of cell membrane during irradiation induces an explosive liberation of the cytoplasm together with parts of the membrane. This response has been observed previously following illumination of Ulocladium sp. at $157 \mathrm{~nm}$ (Sarantopoulou et al., 2006b). Thin layers $0.3 \mathrm{~nm}$ thick were removed per laser pulse from the external protective membrane of Ulocladium sp., which eventually exploded when $45 \mathrm{~nm}$ thick layers were removed from the external membrane.

The survival probability of spores irradiated with $5.4 \times 10^{4} \mathrm{~s}$ (3.18 $\times 10^{24}$ photons $\mathrm{m}^{-2}$ ) is $85 \%$ and $31 \%$ at $10^{5}$ and $10^{-4} \mathrm{~Pa}$ respectively (Tables 23 ). The survival probability at $10^{-4} \mathrm{~Pa}$ is comparable to the survival probability (28\%) of spores irradiated continuously for $8.64 \times 10^{4} s$ with the low intensity hydrogen source ( $8.6 \times 10^{19}$ photons $m^{-2}$,Table 1 ).

The average survival probability of spores is $\sim 100 \%$ for $5.3 \times 10^{23}$ and $1.8 \times 10^{18}$ photons $\mathrm{m}^{-2}$, for high (laser) and low (hydrogen) intensities at $10^{5} \mathrm{~Pa}$ respectively. 
The average survival probability, at high and low photon intensities is 85 and $96 \%$ at $3.18 \times 10^{24}$ and $8.6 \times 10^{19}$ photons $m^{-2}$ respectively.

The survival probability of spores is independent of the VUV photon intensity within the experimental limits, opposite to what is expected, in agreement with previous results at $254 \mathrm{~nm}$ (Rice and Ewell, 2001).

Furthermore, from previous studies of etching rates of different polymeric materials, a $10 \mathrm{Jm}^{-2}$ laser pulse is able to remove approximately $0.5-0.1 \mathrm{~nm}$ thick layers of a typical organic film. In our experimental set up $\left(75 \mathrm{~J} \mathrm{~m}^{-2}\right)$, a $500 \mathrm{~nm}$ thick layer will be ablated with 142-714 laser pulses. However, according to Tables 2 and 3 , the survival probability is still high, following irradiation with $5.4 \times 10^{4}$ laser pulses. These results can be interpreted on the basis of quick formation of a thin carbon layer on the external membrane at higher photon intensities, which further protects the interior of the spores during the irradiation time. The thin layer is formed by the accumulation of carbon photo-products on the surface of the membrane instead of thrusting them away.

\subsection{VUV Irradiation of spores in space}

Suppose that spores are traveling in the solar system in an elliptic orbit and they are directly irradiated with $F$ photons per $m^{2}$ in the time interval $t_{1}-t_{2}$ between two points $P\left(\vec{r}_{1}, t_{1}\right)$ and $P\left(\vec{r}_{2}, t_{2}\right)$ of their trajectory in the VUV, then

$$
\begin{aligned}
& F\left(t_{1}, t_{2}\right)=\int_{t_{1}}^{t_{2}} I(\vec{r}) d t \\
& I(\vec{r})=I\left(\vec{r}_{p}\right) * \frac{\left|r_{p}^{2}\right|}{\left|r^{2}\right|}
\end{aligned}
$$

Where $I(\vec{r})$ and $I\left(\vec{r}_{p}\right)$ are the photon intensities at the distances $\vec{r}$ and $\vec{r}_{p}$ from the Sun and for $|r| \succ\left|r_{p}\right|$

For the elliptic orbit the following equation is valid (Thomson, 1986).

$$
\frac{d \theta}{(1+e \cos \theta)^{2}}=\frac{\left(K r_{p}(1+e)\right)^{1 / 2}}{r_{p}^{2}(1+e)^{2}} d t
$$

Where $e$ is the eccentricity of the trajectory, $\theta$ is the angle between the major axis and the position vector $\vec{r}$ is measured counterclockwise from the focal point (Sun), K is a universal constant equal to $1.32712440018 \times 10^{20} \mathrm{~m}^{3} \mathrm{~s}^{-2}$ for the solar system, and $r_{p}$ is the perigee of the orbit respectively.

From equations $1-3$, the total number of Sun photons per $\mathrm{m}^{2}$ irradiating the spores between two points of their trajectory at $\theta_{1}$ and $\theta_{0}$ is, 
$F\left(\theta_{0}, \theta_{1}\right)=\frac{I\left(r_{p}\right) r_{p}^{2}}{\left(K r_{p}(1+e)\right)^{1 / 2}}\left(\theta_{1}-\theta_{0}\right)$

Where $I\left(r_{p}\right)=10^{15}$ photons $m^{-2} s^{-1}$ (Hardi, 2006; Woods et al., 1994).

For an ideal orbit of transfer of spores between Mars and the Earth ( $r_{p}=1.5 \times 10^{11} \mathrm{~m}, r_{a}=2.03 \times 10^{11} \mathrm{~m}$-perihelion and aphelion of the orbit), the total number of photons per $\mathrm{m}^{2}$, irradiating the spores during the interplanetary trip is $F\left(\theta_{0}, \theta_{1}\right)=3.3 \times 10^{21}$ photons $m^{-2}$ for $\delta \theta=0.25 \pi$.

The photon flux of one laser pulse at $157 \mathrm{~nm}$ is $5.9 \times 10^{19}$ photons puls $\mathrm{e}^{-1} \mathrm{~m}^{-2}$, therefore the equivalent number of VUV solar photons falling on the spores during an interplanetary trip from starting from Mars, is equivalent to the irradiation on Earth with 56 laser pulses at $10^{-4} \mathrm{~Pa}$. From Table 3 the survival probability of spores irradiated with this fluence is $\sim 92 \%$.

Using the low intensity hydrogen source, the $3.3 \times 10^{21}$ photons $\mathrm{m}^{-2}$ at $10^{-4}$ $P a$ and $10 \mathrm{~K}$, correspond to $3.3 \times 10^{6} s$ ( 38 days) of solar VUV irradiation in space near the Earth.

The time $t_{e}$, which is required to trace the above elliptic orbit is given by the equation

$t_{e}=\frac{r_{p}^{3 / 2}}{\left((1-e)^{3} K\right)^{1 / 2}}\left[2 \tan ^{-1}\left(\sqrt{\frac{1-e}{1+e}} \tan \frac{1}{2}\left(\theta_{1}-\theta_{0}\right)\right)-\frac{e \sqrt{1-e^{2}} \sin \left(\theta_{1}-\theta_{0}\right)}{1+e \cos \left(\theta_{1}-\theta_{0}\right)}\right]$

and is $~ 3.6 \times 10^{7} s$ (419 days).

The long term effect of the space vacuum on the survival probability of spores in this direct interplanetary 419 day trip, that represents the minimum time of travelling of spores between the two planets is unknown. In addition the transfer time of Martian meteorites to Earth can range from few hundred days, to millions of years. However taking into consideration, (1) the high survival probability of spores after 4 days at $10^{-4} \mathrm{~Pa}$ and $10 \mathrm{~K}$, (2) the release of proteins that protect the spores against dehydration, then the effect of the space vacuum, the low temperature and the VUV solar irradiation on the survival probability of spores during a direct interplanetary trip, (equivalent to 38 days of laboratory/solar VUV irradiation near the Earth), is expected to be $\sim 61 \%$. The statement of the survival of spores for longer periods of time is further supported by (3) the large survival probability of Aspergillus sp. at low temperature for 18 years of storage (Schipper et al., 1976), (4) the survival probability of the microbial organisms in Antarctica for million of years, (Wynn-Williams and Edwards, 2000; Onofri et al., 2004; Wickeramasinghe, 2004), and (5) the stability of the survival probability of spores after two weeks in vacuum (Brueschke et al., 1961).

\section{Conclusions}

The survival probability of Aspergillus terreus spores in simulated space experiments under solar VUV irradiation during a direct interplanetary transfer from Mars to Earth 
is evaluated. During the trip, the spores are irradiated with the equivalent amount of 54 laser pulses at $157 \mathrm{~nm}$ with $92 \%$ survival probability, or with the equivalent amount of VUV solar photons in space near the earth for 38 days with $61 \%$ extrapolated survival probability under VUV irradiation, space vacuum and low temperature.

The relatively high survival probability of spores in vacuum, low temperature and VUV irradiation is interpreted both theoretically and experimentally on the basis of (1) the activation of a biological functionality of spores in vacuum that prevents further dehydration by covering the external part of the membrane with proteins. The spores retain $34 \%$ and $61 \%$ of their initial water surface density at 298 and $10 \mathrm{~K}$ respectively after 4 days in vacuum, (2) the shielding of the interior of the cells from VUV radiation from a thin carbon layer, which is formed quickly on the external surface of the during the initial moments of the VUV irradiation, (3) the vitrification of the cell content at $10 \mathrm{~K}$, which increases the survival probability at low temperature to $\sim 54 \%$ from $\sim 34 \%$ at $298 K$ (4) The low pumping and cooling rates in vacuum.

\section{Acknowledgements}

The work is part of a joint ESA /EU project (SURE) to estimate the survival probability of spores in space and at the International Space Station.

\section{Author's statement}

All authors were involved in the ESA/EU SURE project and contribute equally to this article. The experiments and tests were carried out at the experimental facility of the National Hellenic Research Foundation in Athens, Greece. The biological samples were prepared in Bucharest by Prof. Ioana Gomoiu. The experiments were carried out by Dr. Evangelia Sarantopoulou, Dr. Zoe Kollia and Prof. Ioana Gomoiu. Dr Alkiviadis-Constantinos Cefalas developed the theoretical model of Appendix A.

\section{Appendix A}

The rate of change of the background pressure $\frac{d P_{e}(t)}{d t}$ is proportional to the pumping speed $\beta(t)$ at time $t$, and inversely proportional to the volume of the vacuum chamber

$V_{c}$.

$$
\frac{d P_{e}(t)}{d t}=-P_{e}(t) \frac{\beta(t)}{V_{c}}
$$

The pumping speed $\beta(t)$ of the rotary pump is not constant in the pressure range from $10^{5}$ to $1 \mathrm{~Pa}$ and is fitted to the equation

$$
\beta(t)=\beta(\infty)+(\beta(0)-\beta(\infty)) e^{-\alpha t}
$$

Where $\beta(0) \approx 1.1 \times 10^{-3}$ and $\beta(\infty) \approx 0.57 \times 10^{3} \mathrm{~m}^{3} \mathrm{~s}^{-1}$ are the pumping speed at $t=0$ and $t \rightarrow \infty$ respectively, $\alpha$ is the rate of change of the pumping speed and is considered to be constant. 
Using equation $A 2$, the solution of equation $A 1$ is

$$
\begin{aligned}
& P_{e}(t)=P_{e}(\infty)+\Delta P_{e} \exp \left(-B_{2}\right) \exp \left(-\left(B_{1} t-B_{2} \exp (-\alpha t)\right) \approx\right. \\
& P_{e}(\infty)+\Delta P_{e} \exp \left(-B_{1} t\right) \quad(A 3)
\end{aligned}
$$

Where $P_{e}(0)=10^{5} \mathrm{~Pa}$ and $P_{e}(\infty)=1 P a$ is the background pressure at $t=0$ and $t \rightarrow \infty$ respectively, and $\Delta P_{e}=P_{e}(0)-P_{e}(\infty)$. By fitting equation $A 3$ to the experimental data of the time dependence of the background pressure, then $B_{1}=\frac{\beta(\infty)}{V_{c}}=0.016 s^{-1}, \quad B_{2}=\frac{1}{\alpha V_{c}}(\beta(0)-\beta(\infty))=0.94$ for the volume of the vacuum chamber $V_{c}=35 \times 10^{-3} \mathrm{~m}^{3}$ and therefore $a=0.011 \pm 0.008 \mathrm{~s}^{-1}$. The change of rate of the pumping speed $\alpha$ is comparable to the inverse characteristic time of the pumping system $B_{1}$, as it is expected.

Furthermore, the survival probability of spores in vacuum is considered to be proportional to the amount of water that remains in the cell. Therefore the normalized concentration of water molecules per unit surface in the cell $N(t) / N(0)$ will follow the time evolution of the experimental survival probability (Fig. 8).

Next we assume that the rate of dehydration $\frac{d N(t)}{d t}$ is proportional to the pumping speed. Based on the experimental evidence of the high survival probability in vacuum after $96 h$, the dehydration rate must come to a halt after some time, and well before the dehydration cease the vital operations of the spores. It is evident therefore that a biological functionality is activating in vacuum to stop dehydration as it is confirmed with the AFM.

Based on the previous assumptions, the dehydration rate in vacuum should be described by a differential equation of the type

$$
\frac{d N(t)}{d t}=-A \beta(t) \exp (-\gamma t)
$$

Where $\mathrm{A}$ is a constant and $\gamma$ is the response rate of the spore that stops dehydration. Using equation $A 3$ the solution of equation $A 4$ is

$$
\begin{aligned}
& N(t)=N(0)+\frac{\gamma(\alpha+\gamma)(N(\infty)-N(0))}{\beta(\infty) \alpha+\beta(0) \gamma}\left[\frac{\beta(\infty)}{\gamma}+\frac{\beta(0)-\beta(\infty)}{(\alpha+\gamma)}-\frac{\beta(\infty)}{\gamma} \exp (-\gamma t)-\right. \\
& \left.-\frac{\beta(0)-\beta(\infty)}{(\alpha+\gamma)} \exp (-(\alpha+\gamma) t)\right]=N(0)-\left((N(0)-\mathrm{N}(\infty))+\mathrm{A}_{1}((\mathrm{~N}(0)-\mathrm{N}(\infty)) \exp (-\gamma \mathrm{t})+\right. \\
& +\mathrm{A}_{2}((\mathrm{~N}(0)-\mathrm{N}(\infty)) \exp (-(\alpha+\gamma) t) \quad(A 5)
\end{aligned}
$$

where

$$
\mathrm{A}_{1}=\frac{(\alpha+\gamma) \beta(\infty)}{\beta(\infty) \alpha+\beta(0) \gamma}, \mathrm{A}_{2}=\frac{\gamma(\beta(0)-\beta(\infty))}{\beta(\infty) \alpha+\beta(0) \gamma}
$$


The constants $\gamma$ and $B_{1}$ determine the rate of dehydration. $N(0)$ and $N(\infty)$ is the surface density of water (number of water molecules per unit surface) at $t=0$ and $t \rightarrow \infty$ respectively.

Next, the dehydration parameter $x(t)$ is defined as $x(t)=\frac{N(0)-N(t)}{N(0)}$

Taking into consideration that the survival probability $(S P(t))$ will be directly dependent on the relative concentration of water remaining in the spore $\frac{N(t)}{N(0)}$, then $x(t)=1-S P(t)$ and by putting $x=x(\infty)$, equation $A 5$ becomes

$N(t)=N(0)\left[(1-x)+A_{1} x \exp (-\gamma t)+A_{2} x \exp (-(\gamma+\alpha) t)\right] \quad(A 6)$

Best fit of equation $A 6$ to Fig. 8 is for $\gamma=(1.9 \pm 0.49) \times 10^{-3} s^{-1}, \alpha=(1.1 \pm 0.8) x 10^{-2} s^{-1} x=0.67 \pm 0.04$ (Table4).

The value of the rate of change of the pumping speed $\alpha$ is comparable to its value from equation $A 3$ within the experimental error.

Next, we consider a thick parallelepiped section between two thin membrane layers with area $d S$ filled with water of mass $m(t)$ and separated by $y(t)$. Then $y(t)=\frac{N(t) W}{N \rho}$, where $W, \rho, N$ are the molecular weight, the density of the water, and the Avogardo's number respectively. The separation of the layers at $t=0$ and $t \rightarrow \infty$ is $y(0)=\frac{N(0) W}{N \rho}$ and $y(\infty)=\frac{N(\infty) W}{N \rho}$.

The hydration pressure $P_{h}(t)$ is an exponential function of the separation $y(t)$ between the two membrane layers

$$
P_{h}(t)=C P_{h}(0) \exp \left(\frac{D}{y(t)}\right)
$$

where $P_{h}(0)$ is the hydration pressure when the layers are separated by the characteristic hydration length $D \approx 2 \times 10^{-10} \mathrm{~m}$, and $C$ is a constant.

Equation $A 7$ then becomes

$$
P_{h}(t)=C P_{h}(0) \exp \left(\frac{N \rho D}{N(t) W}\right)=C P_{h}(0) \exp \left(\frac{N(D)}{N(t)}\right)
$$

Where $N(D)=\frac{D N \rho}{W} \approx 8.36 \times 10^{15} \mathrm{~m}^{-2}$ is the water's surface density between two layers separated by the distance $D . \quad N(D)=N(0)$ and $C=\exp (-1)$

Using equation $A 6$, equation $A 8$ becomes, 
$P_{h}(t)=0.36 P_{h}(0) \exp \left[(1-x)+A_{1} x \exp (-\gamma t)+A_{2} x \exp (-(\gamma+\alpha) t)\right]^{-1}$

Equations $A 8$ and $A 9$ describe the time dependence of the hydration stress as a function of the pumping rate and the biological functionality of the membrane.

The overall stress on the membrane $\Delta P(t)$ will be the difference between the hydration and the background stress and from equations $A 3$ and $A 9$ we get

$$
\begin{aligned}
& \Delta P(t)=0.36 P_{h}(0) \exp \left[(1-x)+A_{1} x \exp (-\gamma t)+A_{2} x \exp (-(\gamma+\alpha) t)\right]^{-1}- \\
& -P_{e}(\infty)+\Delta P_{e} \exp \left(-B_{1} t\right) \quad(A 10)
\end{aligned}
$$

Taking into consideration that $P_{h}(t) \succ \succ P_{e}(t)$, equation $A 10$ becomes

$$
\Delta P(t) \approx 0.36 P_{h}(0) \exp \left[\left((1-x)+A_{1} x \exp (-\gamma t)+A_{2} x \exp (-(\gamma+\alpha) t)^{-1}\right)=0.36 P_{h}(0) F(x, t)\right.
$$

Equation $A 11$ is the final result (Fig.18). It describes the time evolution of the overall stress on the spore as a function of the hydration parameter $x$, the pumping speed change rate $\alpha$ and the reaction rate of the spore $\gamma$.

The overall stress exerted on the membrane can be estimated from the deformation of the spores as it is measured from the AFM images.

The relative strain $\frac{\xi_{\vec{e}_{j}}(t)-\xi_{\vec{e}_{j}}(0)}{\xi_{\vec{e}_{j}}(0)}$ along a direction $\vec{e}_{j}$ will be proportional to the strain vector $T_{e l}{ }^{\left(\vec{e}_{j}\right)}$

$$
\frac{\xi_{\vec{e}_{j}}(t)-\xi_{\vec{e}_{j}}(0)}{\xi_{\vec{e}_{j}}(0)}=E T_{e l}{ }^{\left(\vec{e}_{j}\right)}
$$

where $E \approx 9 G P a$ is the Young modulus of the membrane and taking into consideration that

$$
T_{e l}^{\left({ }^{\left(\vec{e}_{j}\right)}\right.}(t)=f(E) \Delta P(t)
$$

then equation $A 12$ becomes

$$
r(t)=r(0)\left[1+\frac{1}{E} f(e) \Delta P(t)\right]
$$

where $\xi_{\vec{e}_{j}}=r(t), \xi_{\vec{e}_{j}}(0)=r(0), r(t)$ and $r(0)$ is the length of the major semi-axis of the spore at $\mathrm{t}$ and $t=0$ respectively, $f(e)$ is a constant depending on the eccentricity $e$ of the ellipsoid shape of spores.

From the experimental data, the average eccentricity of the spores prior and after the exposure in vacuum is 0.68 and 0.72 respectively (Fig.5, 9, 10,12-16). In addition for an ellipsoid shape with the specified eccentricities a typical value of 
$f(e)$ along the major and minor axes is $f(e)=4$ and $f(e)=0.5$ respectively, (Sadowsky, and Sternberg 1949).

Finally from equations $A 11$ and $A 14$ the overall stress on spores can be evaluated from their deformation and the Young modulus.

$\Delta P(\infty)=\left(\frac{r(\infty)}{r(0)}-1\right) \frac{E}{f(e)} \Rightarrow P_{h}(0)=\frac{2.71 E}{f(e) F(x, \infty)}\left(\frac{r(\infty)}{r(0)}-1\right) \quad(A 15)$

For the current experimental configuration $F(x, t) \in[1.44,2.71]$. 


\section{References}

Amils, R., Gonzáles-Toris, E., Fernádez-Remolar, D., Gómez, F., Aquilera, A., Rodríguez, N., Malki, M., García-Moyano, A., Fairén, A.G., de la Fuente, V.; Sanz, J. L., 2007. Extreme environments as Mars terrestrial analogues: The Rio Tante Case. Planet. Space Sci. 55, 370-381.

Arrhenius, S., 1908. Worlds in the Making, Harper \& Brothers, London.

Baker, S.M., Margison, G.P., Strike, P., 1992. Inducible alkyltransferase DNA repair proteins in the filamentous fungus Aspergillus nidulans. Nucleic Acids Res. 20, 645651.

Bosmans, J., 1974. Ten Years Lyophilization of pathogenic fungi. Mycopathologia et Mycologia applicata. 3, 13-23.

Boyd-Wilson, K.S.H., Perry, J.H., Walter, M., 1998. Persistence and survival of saprophytic fungi antagonistic to otrytis Cinerea on kiwifruit leaves. Conference proceedings of the New Zealand Plant Protection Society Incorporating 96-101.

Brueschke, E.E., Suess, R.H., Willard, M., 1961. The survival probability of microorganisms in ultra-high vacuum, Planet. Space Sci 8, 30-34.

Bryant, G., Wolfe, J., 1992. Interfacial forces in cryobiology and anhydrobiology. Cryo-Letters 13, 23-36.

Bucker, H., Horneck, G., Wollenhaupt, H., Schager, M., Taylor, Gr., 1974. Survival probability of Bacillussubtilis spores exposed to space environment in the M-191 experiment system aboard Apollo 16. Life Sci. Space Res. 12, 209-213.

Burchell, M.J., Mann, J.R., Bunch, A.W., 2004. Survival of bacteria and spores under extreme shock pressures. Monthly Notices of the Royal Astronomical Society $352,1273-1278$.

Calvori, C., Morpugo, G., 1966. Analysis of induced mutations in Aspergillus nidulans. I. UV- and HN0,-induced mutations. Mutation Res. 3, 145-151.

Castle, E.S., 1945. The Structure of the Cell Walls of Aspergillus and the Theory of Cellulose Particles. Am. J. Bot. 32, 148-151.

Cefalas, A.C., Skordoulis, C., Kompitsas, M., Nicolaides, C.A., 1985. Gain measurements at $157 \mathrm{~nm}$ in an $\mathrm{F}_{2}$ pulsed discharge molecular laser. Opt. Commun. $55,423-426$.

Cefalas, A.C., Dubinskii, M.A., Sarantopoulou, E., Abdulsabirov, R.Yu., Korableva, S.L., Naumov, A.K., Semashko, V.V., Nicolaides, C.A., 1993. On the Development of New VUV and UV Solid-State Laser Sources for Photochemical Applications. Laser Chem. 13, 143-150. 
Cefalas, A.C., Sarantopoulou, E., Kollia, Z., 2001. Efficient removing of foxing from a medieval Ptolemaic map using a molecular laser at 157nm. Appl. Phys. A 73, 571578.

Cefalas, A.C., Sarantopoulou E., Gogolides E., Argitis P., 2000. Absorbance and outgasing of photoresist polymeric materials for UV lithography below $193 \mathrm{~nm}$ including $157 \mathrm{~nm}$ lithography. Microelectron. Eng. 53, 123-126.

Cefalas, A.C., Sarantopoulou, E., Kollia, Z., 2001. Efficient removing of foxing from a medieval Ptolemaic map using a molecular laser at 157nm. Appl. Phys. A. 73, 571578.

Cefalas, A.C., 2005. Current trends in $157 \mathrm{~nm}$ dry lithography. Appl. Surf. Sci. 247, 577-583.

Chang, L., Lennox, J. E., Tuveson, R.W., 1968. Induced mutation in UV-sensitive mutants Aspergillus nidulans and Neurospora crassa. Mutation Res. 5, 217-224.

Claverie-Martin, F., Diaz-Torres, M.R., Geoghegan, M.J., 1998. Chemical composition and ultrastructure of wild-type and white mutant Aspergillus nidulans conidia walls. Curr. Microbiol. 16, 281-287.

Cole, G.T., Sekiya T., Kasai R., Yokoyama T., Nozawa Y., 1979. Surface ultrastructure and chemical composition of the cell walls of conidial fungi. Exp. Mycol. 3, 132-156.

Davis, D. J., Burlak, C., Money, N. P., 2000. Osmotic pressure of fungal compatible osmolytes. Mycol. Res. 104, 800-804.

Dever, J.A., Pietromica, A.J., Stueber, T.J., Sechkar, E. A., Messer, R.K., 2002. Simulated Space Vacuum Ultraviolet (VUV) Exposure Testing for Polymer Films. NASA/TM-2002-211337.

Diaz, B., Schulze-Makuch, D., 2006. Microbial survival rates of Escherichia coli and Deinococus radiodurans under low temperature, low pressure and UV-irradiation conditions and their relevance to possible Martial life. Astrobiology 6, 332-346.

Douvas, A.M., Petrou, P.S., Kakabakos, S.E., Misiakos, K., Argitis P., Sarantopoulou, E., Kollia, Z., Cefalas, A.C., 2005. 157-nm laser ablation of polymeric layers for fabrication of biomolecule microarrays. Anal. Bioanal. Chem. 381, 1027-1032.

Dublin, M., Volz, P., 1973. Space related research in mycology concurrent with the first decade of manned space exploration. Origin Life Evol. 4, 223-230.

Dufrêne, Y.F., Boonaert, C.J.P, Gerin, P.A., Asther M., Rouxhet P.G., 1999. Direct Probing of the Surface Ultrastructure and Molecular Interactions of Dormant and Germinating Spores of Phanerochaete chrysosporium. J. Bacteriol. 181, 5350-5354.

Dufrene, Y.F., 2002. Atomic Force Microscopy, a Powerful Tool in Microbiology. Journ. Bacteriol. 184, 5205-5213. 
Dute, R.R., Weete, J.D., Rushing, A.E., 1989. Direct Probing of the Surface Ultrastructure and Molecular Interactions of Dormant and Germinating Spores of Phanerochaete chrysosporium. Mycologia 81, 772.

Ellis, J.J., Roberson J.A., 1968. Survival probability of Fungus Cultures Preserved by Lyophilization. Mycologia 60, 399-405.

Ellis, D. H., 1978. Fine structure of spore germination in Epicoccum purpurascens. Trans. Br. Mycol. Soc. 70,170-173.

Fairén, A., Dohm, J. M., Uceda, E. R., Rodríge, A. P., Baker, V. R., FernándezRemmolar, D., Schultze-Makuch, D., Amils, R. 2005. Prime candidate sites for astrobiologicalexploration through the hydrogeological history of Mars. Planet. Space Sci., 53, 1355-1375.

Fekete, A., Foldvari, I., Hegedus, M., Módos, K., Rontó, G., Kovács G., Bérces, A., Péter, A., 2003. Study of the effect of simulated space environment on phage T7 and isolated T7 DNA thin films. J. Luminescence 102-103, 469-475.

Flentje, N.T., Stretton, H., McKenzie, A.R., 1967. Mutation in Thanatephorus cucumeris. Australian J. Biol. Sci.20, 1173-1180.

Goldman, G.H., McGuire S. L., Harris S. D. 2002. The DNA Damage Response in Filamentous Fungi. Fungal Genet Biol. 35, 183-95.

Gorny, R.L., 2004. Filamentous micro organisms and their fragments in indoor air - A review. Ann. Agric. Environ. Med. 11, 185-197.

Gorbushina A., 2003. Microcolonial Fungi: Survival Potential of Terrestrial Vegetative Structures. Astrobiology 3, 543-554.

Grebeshova, R.N., 1964. Biochemical Characteristics of aspergillus UV mutants. Microbiol. (USSR) (Engl. Transl.) 33, 971-974.

Greenberg, J.M., Weber, P., Schutte, W., 1984. Chemical and biological evolution in space. Adv. Space Res. 4, 41-49.

Hahn, A., Hock, B., 1999. Chromosome mechanics of fungi under spaceflight conditions - tetrad analysis of two-factor crosses between spore color mutants of Sordaria macrospora. FASEB J. 13, S149-S156.

Hanlin, R.T., 1976. Phialide and Conidium Development in Aspergillus clavatus. Am. J. Bot. 63, 144-155.

Hardi P., 2006. First VUV full-Sun spectrum of the transition region with high spectral resolution compared to cool stars. Astron. Astrophys. 449, 759-768. 
Heise, M., Neff, W., Franken, O., Muranyi, P., and Wunderlich, J., 2004. Sterilization of Polymer Foils with Dielectric Barrier Discharges at Atmospheric Pressure. Plasmas Polym. 9, 23-33.

Hieda, K., 1994. DNA damage induced by vacuum and soft X-ray photons from synchrotron radiation. Int. Journ. Radiat. Biol. 66, 561-567.

Horikoshi, K., Iida, S., 1964. Studies of the Spore Coats of Fungi. I. Isolation and Composition of the Spore Coats of Aspergillus oryzae. Biophys. Acta 83, 197-203.

Horneck, G., Bucker, H., Wollenhaupt, H., 1971. Survival of bacterial spores under some simulated lunar surface conditions. Life Sci. Space Res. 9, 119-24.

Horneck, G., Bucker, H., Dose, K., Martens, K. D., Mennigmann, H. D., Reitz, G., Requardt, H., Weber, P.,1984. Photobiology in space: An experiment on space lab I. Orig. Life Evol. Biosph. 14, 825-832.

Horneck G., 1988. Impact of space flight environment on radiation response. In: McCormack P.D., Swenberg C.E., Bücker H. (Eds), Terrestrial Space Radiation and Its Biological Effects, Plenum, New York, pp. 707-714.

Horneck, G., 1995. Exobiology, the study of the origin, evolution and distribution of life within the contex of cosmic evolution, a review. Planet. Space Sci., 43, 189-217.

Horneck, G., 1999. European activities in exobiology in earth orbit: results and perspectives. Adv. Space Res. 23, 381-386.

Horneck, G., 2000. The microbial world and the case of Mars. Planet. Space Sci. 48, 1053-1063.

Horneck, G., Rettberg, P., Reitz, G., Wehner, J., Eschweiler, U., Strauch, K., Panitz, C., Starke, V., Baumstark-Khan, C., 2001. Protection of bacterial spores in space, a contribution to the discussion on Panspermia. Orig. Life Evol. Biosph. 31, 527-547.

Horneck, G., Mileikowsky, C., Melosh, H.J., Wilson, J.W., Cucinotta, F.A., and Gladman, B., 2002. Viable transfer of microorganisms in the solar system and beyond, in G. Horneck and C. Baumstark-Khan (Eds.), The Quest for the Conditions of Life. Springer, Berlin, pp.57-76.

Hoyle, F., Wickramasinghe, N.C., Astronomical Origins of Life: Steps Towards Panspermia, in Hoyle, F., Wickramasinghe, N.C., (Eds.), Kluwer Academic Publishers, 2000.

Imshenetskii, A.A. ; Kuzyurina, L.A., 1966. Variability in Asperfillus niger induced by the combinedeffect of ethylenimine and ultraviolet irradiation. Microbiology (USSR) (Engl. Transl.), 35: 688-91(Sept.-Oct. 1966). 
Jakuboska, J., Oberman, H., Makiedonska, A., Florianowicz, T., 1967. The itaconic and itatartaric acid formation by UV and gamma irradiated isolates of Aspergillus terreus NRRL, Acta Microbiol. Pol. 16, 53-68.

Käfer, E., Chen, T.L., 1964. Translocations and recessive lethals induced in Aspergillus by ultra-violet light and gamma-rays. Can. J. Genet. Cytol. 6, 249-254.

Kaminskyj, S.G.W., Boire, M.R., 2004. Ultrastructure of the Aspergillus nidulans hypA1 restrictive phenotype shows defects in endomembrane arrays and polarized wall deposition. Can. J. Bot. 82, 807-814.

Kawamura, C., Tsujimoto, T., Tsuge, T., 1999. Targeted Disruption of a Melanin Biosynthesis Gene Affects Conidial Development and UV Tolerance in the Japanese Pear Pathotype of Alternaria alternate. Mol. Plant Microbe In 12, 59-63.

Kern, V.D., Hock, B., 1993. Fungi in space-literature survey on fungi used for space research. Microgravity Sci Technol. 6, 194-206.

Koike, J., Oshima, T., Koike, K.A., Taguchi, H. 1992. Survival rates of some terrestrial microorganisms under simulated space conditions, Adv. Space Res. 12, 271-274.

Koike, J., Oshima, T., Kobayashi, K., Kawasaki, Y., 1995. Studies in the search for life on Mars. Adv. Space Res. 15, 211-214.

Kollia, Z., Sarantopoulou, E., Cefalas, A.C., Kobe, S., Samardzija, Z., 2004. Nanometric size control and treatment of historic paper manuscript and prints with laser light at $157 \mathrm{~nm}$. Appl. Phys. A 79, 379-382 .

Krumbein, W.E., Gorbushina, A.A., Holtkamp-Tacken, E., 2004. Hypersaline Microbial Systems of Sabkhas: Examples of Life's Survival in "Extreme" Conditions. Astrobiology 4, 450-459.

Leach C. M., 1971. A practical guide to the effects of visible and ultraviolet light on Fungi. Methods in Micro. 4, 609-664.

Lindberg, C., Horneck, G., 1991. Action Spectra for Survival and Spore Photoproduct Formation of Bacillus subtilis Irradiated with Short-wavelength (200-300 nm) UV at Atmospheric Pressure and in Vacuo. J. Photochem. Photobiol. B: Biol. 11, 69-80.

Ma, H., Snook, L.A., Kaminskyj, S.G.W., Dahms, T.E.S., 2005. Surface ultrastructure and elasticity in growing tips and mature regions of Aspergillus hyphae describe wall maturation. Microbiology 151, 3679-3688.

Martin, F.C., Diaz-Torres, M.R., Geoghegan, M.J., 1988. Chemical composition and ultrastructure of wild-type and white mutant Aspergillus nidulans conidial walls. Curr. Microbiol. 16, 281- 287.

Matsushima, K., Shimada, K., 1967. Proteolytic systems of uv mutants of Aspergillus niger. Nippon Nogei Kagaku Kaishi 41, 671-674. 
Mautner M.N., 2002. Planetary Resources and Astroecology. Planetary Microcosm Models of Asteroid and Meteorite Interiors: Electrolyte Solutions and Microbial Growth- Implications for Space Populations and Panspermia. Astrobiology 2, 59-76.

May, G.S., Adams, T.H., 1997. The Importance of Fungi to Man. Genome Res. 7, 1041-1044.

Mazur, P., 1984. Freezing of living cells: mechanisms and implications. Am. J. Physiol. Cell Physiol. 16, C125-C142.

Mazur, P., 1960. Physical factors implicated in the death of microorganisms at subszero temperatures. Ann. N. Y. Acad. Sc. 85, 610-629.

Mazur, P 1961. Physical and temporal factors involved in the death of yeast at subzero temperature, Biophys. J. 1, 247-264.

McLean, R.J.C, Welsh, A.K, Casasanto, V.A. 2006. Microbial survival in space shuttle crash. Icarus 181, 323-325.

Mert H.H. and Dizbay M., 1977. The effect of osmotic pressure and salinity of the medium on the growth and sporulation of Aspergillus niger and Paecilomyces lilacinum species. Mycopathologia 61, 125-127

Mishra, A.K., Nandi, P., 1959. Ultraviolet induced biochemical mutations in Aspergillus niger. Sci. Cult. 25, 81.

Nicholson, W.L., Munakata, N., Horneck, G., Melosh, H. J., Setlow P., 2000. Resistance of Bacillus Endospores to Extreme Terrestrial and Extraterrestrial Environments. Microbiol. Mol. Biol. R. 64, 548-572.

Nicholson, W.L., Schuerger, A.C., Setlow, P., 2005. The solar UV environment and bacterial spore UV resistance: considerations for Earth-to-Mars transport by natural processes and human spaceflight. Mutat. Res. 571, 249-264.

Novikova, N., De Boever P., Poddubko, S., Deshevaya, E., Polikarpov, N., Rakova, N., Coninx, I., Mergeay, M., 2006. Survey of environmental biocontamination on board the International Space Station. Res. Microbiol. 157, 5-12.

Nussinov, M. D., Lysenko, S.V., 1983. Cosmic vacuum prevents radiopanspermia. Origins Life Evol B 13, 153-164.

Onofri, S., Selbmann, L., Zucconi, L., Pagano, S. 2004. Antarctic microgungi as models for exobiology. Planet. Space Sci. 52, 229-237.

Paulino-Lima, I.G., Pilling, S., Janot-Pacheco, E., Naves deBrito A., Ribeiro Barbosa, J.A.R.G., Leitao, A.C., Lage, C.A.S., 2010. Laboratory simulation of interplanetary ultraviolet radiation (broad spectrum) and its effects on Deinococcus radiodurans. Planet. Space Sci. 58, 1180-1187. 
Rettberg, P., Rabbow, E., Panitz, C., Reitz, G., Horneck, G., 2002. Survivability and protection of bacterial spores in space - the BIOPAN experiment. Proceedings of the First European Workshop on Exo-Astrobiology Graz, Austria. Ed.: Huguette Lacoste. ESA SP-518, Noordwijk, Netherlands: ESA Publications Division, 105-108.

Rice, J.K., Ewell, M., 2001. Examination of peak power dependence in the UV inactivation of bacterial spores. Appl. Environ. Microbiol. 67, 5830-5832.

Romano, C., Maritati, E., Paccagnini, E., Massai, L., 2004. Onychomycosis due to Ulocladium botrytis Fallbericht. Onychomykose durch Ulocladium botrytis. Mycoses 47, 346-348.

Rontó, Gy., Bérces, A., Fekete, A., Kovács G., Grof, P., Lammer H., 2004. Biological UV docimeters in simulated space conditions. Adv. Space Res. 33, 13021305.

Rotem, J., Wooding, B., Aylor, D.E., 1985. The role of solar radiation, especially ultraviolet, in the mortality of fungal spores. Phytopathology 75, 510-514.

Rothschild, L.J., Mancinelli, R.L., 2001. Life in extreme environments. Nature 409, 1092-1101.

Sadowsky, M.A, Sternberg, E, 1949, Stress concentation around a triaxial ellipsoidal Cavity. Journ. of Appl. Mechanics, 16, 149-157.

Saffary, R. Nandakumar, R., Spencer, D., Robb, F.T., Davila, J.M., Swart, M., Ofman, L., Thomas, R.J., DiRugiero, J., 2002. Microbial survival of space vacuum and extreme ultraviolet irradiation. Strain isolation and analysis during a rocket flight. FEMS Microbiol. Lett. 215, 163-168.

Sarantopoulou, E., Kollia, Z., Cefalas, A.C., Dubinskii, M.A., C.A. Nicolaides, Abdulsabirov R.Yu., Korableva, S.L., Naumov, A.K., Semashko, V.V., 1994.Vacuum ultraviolet and ultraviolet fluorescence and absorption studies of $\mathrm{Er}^{3+}$-doped LiLuF, single crystals. Appl. Phys. Lett. 65, 813-815.

Sarantopoulou E., Kollia Z., Kocevar K., Musevic I., Kobe S., Drazic G., Gogolides E., Argitis P., Cefalas A.C., 2003. The challenges of $157 \mathrm{~nm}$ nanolithography: surface morphology of silicon-based copolymers. Mater. Sci. Eng. C 23, 995-999.

Sarantopoulou, E., Kollia, Z., Gomoiu, I., 2006a. Preventing biological activity of Ulocladium sp in artifacts using $157 \mathrm{~nm}$ laser. Appl. Phys. A 83, 663-668.

Sarantopoulou, E., Kollia, Z., Cefalas, A.C., Samardžija, Z., Kobe, S., $2006 b$. Preparation of ultra-thin films of DNA bases with laser light at $157 \mathrm{~nm}$. Thin Solid Films, 495, 45-50.

Sarantopoulou E., Kollia, Z., Cefalas, A.C, Manoli, K., Sanopoulou, M., Goustouridis, D., Chatzandroulis S., Raptis, I.. 2008. Surface nano/micro functionalization of PMMA thin films by $157 \mathrm{~nm}$ irradiation for sensing applications. Appl. Surf. Sci. 254, 1710- 1719. 
Sarantopoulou, E., Kollia, Z., Cefalas, A.C., Siokou, A.E., Argitis, P., Bellas, V., Kobe, S., 2009. Surface modification of polyhedral oligomeric silsesquioxane block copolymer films by $157 \mathrm{~nm}$ laser light. J. Appl. Phys. 105, 114305-114311.

Schipper, M.A.A, Bekker-Holtman, J., 1976. Survival probability of lyophilized fungal cultures. Antonie van Leeuwenhoek 42, 325-328.

Schuerger A.C., Richards, J.T., Hintze, P.E., Kern, R.G., $2005 . \quad$ Surface Characteristics of Spacecraft Components Affect the Aggregation of Microorganisms and May Lead to Different Survival Rates of Bacteria on Mars Landers. Astrobiology $5,545-559$.

Setlow P., 1995. Mechanisms for the Prevention of Damage to DNA in Spores of Bacillus Species. Annu. Rev. Microbiol. 49, 29-54.

Silverman, G. J, Davis, N. S., Beecher, N., 1966. Resistivity of spores to ultraviolet and $\gamma$ radiation while exposed to ultrahigh vacuum or at atmospheric pressure. Appl. Microbiol. 15, 510-515.

Swanson, C.P., 1952. The effect of supplementary factors on the radiation-induced frequency of mutations in Aspergillus terreus. J. Cell. Comp. Physiol. 39 (Suppl. 1), $27-38$.

Szewczyk, N.J., Mancinelli, R.L., Mc Lamb, W., Reed, D., Blumberg, B.S., Conley, C. A., 2005. Caenorhabditis elegans survives atmospheric breakup of STS-107, Space Shuttle Columbia. Astrobiology 5, 690-705.

Talbot, N., 2001. Molecular and Cellular Biology of Filamentous Fungi. Oxford University Press.

Thomson, W.T., 1986. Introduction to space dynamics. Dover Publications, Inc., New York.

Tuleta M., Gabla L., Szkarlat A., 2005. Low-energy ion bombardment of frozen bacterial spores and its relevance to interplanetary space. Europhys. Lett. 70, 123-128.

Van der Aa, B.C., Asther, M., Dufrene, Y.F., ,2002. Surface properties of Aspergillus oryzae spores investigated by atomic force microscopy. Colloid. Surface B 24, 277284.

Volz, P., Dublin, M., 1973. Filamentous Fungi exposed to spaceflight stresses including known levels of ultraviolet radiation. Space Life Sci. 4, 402-414.

Wainwright, M., Weber, P.K., Smith, J.B., Hutcheon, I.D. Klyce, B., Wickramasinghe, N.C., Narlikar, J.V, Rajaratnam, P., 2004. Studies on bacteria-like particles sampled from the stratosphere. Aerobiologia 20, 237-240.

Wekhof, A., Trompeter, J., Franken, O., 2001. Pulsed UVB Disintegration (PUVBD): a new sterilization mechanism for broad medical-hospital and packaging applications. 
Proceedings of the First International Congress on Ultraviolet Technologies, USA. June 14-16 Washington D.C., USA

Weber, P., Greenberg, J.M., 1985. Can Spores Survive in Interstellar Space? Nature 316, 403-407.

Wickramasinghe, N.C., 2004. The universe: a cryogenic habitat for microbial life. Cryobiology 48, 113-125.

Wickramasinghe, N.C, Wickramasinghe, J.T, 2003. Radiation pressure on bacterial clumps in the solar vicinity and their survival between interstellar transits. Astrophys. Space Sci. 286, 453-459.

Wix, G., Natonek, M., Kovacs, M., 1959. On the effect of ultraviolet irradiation on the steroid-oxidation capacity of Aspergillus niger. Acta Microbiol. Acad. Sci. Hung. 6, 197-202.

Wolfe, J., Bryant, G., 1999. Freezing, drying and/or vitrification of membrane-solutewater systems. Cryobiology 39, 103-129.

Wolfe, J., Bryant, G., 2001. Cellular cryobiology: thermodynamic and mechanical effects. International Journal of Refrigeration 24, 438-450.

Woods, T.N., Rottman, G.J., Bailey, S., Solomon, S.C., 1994. Vacuum-ultraviolet instrumentation for solar irradiance and thermospheric airglow. Optical Eng. 33, 438444.

Wynn-Williams, D.D, Edwards, H.G.M. 2000. Antarctic ecosystems as models for extraterrestrial surface habitats. Planet. Space Sci. 48, 1065-1075.

Yarwood, C.E., 1950. Water containt of fungi spores. Am. J. Bot. 37, 636-639.

Zimmermann, M.W., Gartenbach, K.E., Kranz, A.R., 1994. First radiobiological results of LDEF-1 experiment A0015 with Arabidopsis seed embryos and Sordaria fungus spores. Adv. Space Res. 14, 47-51.

Zhao, L., Schaefer, D., Marten, M.R., 2005. Assessment of elasticity and topography of Aspergillus nidulans spores via atomic force microscopy. Appl. Environ. Microbiol. 71, 955-960.

Zhao, L.M., Schaefer, D., Xu, H.X., Modi. S.J., LaCourse, W.R., Marten, M.R., 2005. Elastic properties of the cell wall of Aspergillus nidulans studied with atomic force microscopy. Biotechnol. Progr. 21, 292-299.

\section{Figure captions}


Fig.1 VUV spectrum of the hydrogen photon source with maximum emission at 157 $n m$ from the dipole transition between the $\mathrm{B}^{1} \Pi^{+}{ }_{\mathrm{u}} \rightarrow \mathrm{X}{ }^{1} \Sigma^{+}$g electronic states of the molecular hydrogen. The photon intensity of the source is $10^{15}$ photons $m^{-2} \mathrm{~s}^{-1}$.

Fig.2 Experimental configuration of the irradiating system at low VUV photon intensity of the hydrogen source. The spores are irradiated with photon intensity equivalent to the solar VUV photon intensity near the earth. The system consists of (from left to right): 1) The VUV hydrogen source 2) the vacuum chamber 3) the $\mathrm{He}$ cryostat 5) the VUV monochromator.

Fig.3 High VUV photon intensity $\left(9 \times 10^{27}\right.$ photons pulse $\left.e^{-1} \mathrm{~m}^{-2} \mathrm{~s}^{-1}\right)$ laser system. It includes the $157 \mathrm{~nm}$ molecular fluorine laser, the high vacuum chamber with the micro-translational stage and the focused optics. The spores are placed on the X-Y-Z micro- translational stage at $10^{-4} \mathrm{~Pa}$ and $298 \mathrm{~K}$.

Fig.4 High VUV photon intensity laser system operating in nitrogen high pressure optical path purged with nitrogen. It includes the $157 \mathrm{~nm}$ molecular fluorine laser, the nitrogen chamber and the focusing optics. The spores are placed on the top of a micro-translational X-Y-Y- $\theta$ stage. The laser beam is focused with $10 \mu \mathrm{m}$ accuracy. The accuracy of the micro-translational X-Y-Y- $\theta$ stage was $2 \mu m$ and it was controlled with a CCD camera.

Fig.5 (a) Optical image of one Aspergillus terreus spore immobilized on the silica wafer. The average size of spores is $\sim 3 \mu \mathrm{m}$.

(b) 2D-AFM image of one Aspergillus terreus spore with 100-200 $\mathrm{nm}$ granular star structure around the periphery of its elliptic shape.

Fig.6 (a) 3D-AFM image of a part of the surface of Aspergillus terreus spore with rough vesicle structures. (b) 2D-AFM image of conidiophore elongated structure.

Fig.7 AFM high resolution image (phase mode) of one Aspergillus terreus spore with $20 \mathrm{~nm}$ wide rodlet structure on granular domains.

Fig.8 Survival probability of Aspergillus terreus spores at different exposure time and conditions. (@) $\mathrm{P}=10^{-4} \mathrm{~Pa}, \mathrm{~T}=10 \mathrm{~K} .(\bullet) \mathrm{P}=10^{-4} \mathrm{~Pa}, \mathrm{~T}=298 \mathrm{~K}, \mathrm{~F}=10^{15}$ photons $\mathrm{m}^{-2} \mathrm{~s}^{-1}$. The average RMS deviation of the experimental values is $\sim 21 \%$. The pumping rate is $134 \mathrm{~Pa} \mathrm{~s}^{-1}$.

Fig.9 AFM image of damaged Aspergillus terreus spores after $24 h$ at $10^{-4} \mathrm{~Pa}$. The damaged spores appear with extended rod-like structure on the surface (Point AFig.9), indicating excessive biological activity.

Fig.10 AFM image of damaged dehydrated spores after $24 \mathrm{~h}$ at $10^{-4} \mathrm{~Pa}$ and $298 \mathrm{~K}$. The shape of cells is deformed and some parts of spores are squeezed. The cellular content of exploded spores is spread around.

Fig.11 (a) Optical image of an area of the wafer with spores prior to exposure in vacuum. (b) The optical image of the same area after $24 \mathrm{~h}$ at $10^{-4} \mathrm{~Pa}$ and $298 \mathrm{~K}$. The density of spores is lesser than of the non-exposed sample due to dehydration. 
Fig.12 (a) AFM image of a damaged dehydrated Aspergillus terreus spore exposed at $10 \mathrm{~K}$ and $10^{-4} \mathrm{~Pa}$ for $24 \mathrm{~h}$.(b) AFM of an intact spore (A) and a damaged one (B) at the same experimental conditions.

Fig.13 AFM image of Aspergillus terreus spores following $24 h$ at VUV irradiation at $10^{-4} \mathrm{~Pa}$ and $10 \mathrm{~K}$. Some cracks and holes appear on the external membrane of spores (A). The cellular content of exploded spores, 100-200 $\mathrm{nm}$ wide is spread around (B).

Fig.14 AFM image of Aspergillus terreus spore exposed at $10 \mathrm{~K}$ in vacuum $10^{-4} \mathrm{~Pa}$ for $24 \mathrm{~h}$. One spore with dimension $2 \mu \mathrm{m} \times 1.6 \mu \mathrm{m}$ together with the spore's 's remnants is indicated.

Fig.15 AFM image of a damaged Aspergillus terreus spores after $60 \mathrm{~min}$ of laser irradiation in vacuum with a hole at the centre. Part of the cellular content is shown. next to the spore.

Fig.16 AFM image of damaged spores after $60 \mathrm{~min}$ of laser irradiation at $10^{-4} \mathrm{~Pa}$. The cellular content is scattered around.

Fig.17 Survival probability of spores following laser irradiation at $157 \mathrm{~nm}, 15 \mathrm{~Hz}$ at $10^{-4} \mathrm{~Pa}$ and in nitrogen at $10^{5} \mathrm{~Pa}$ at 10,30 and $60 \mathrm{~min}$ respectively.

Fig.18 Time evolution of the relative hydration stress $\Delta P(t) / P_{h}(0)$ of spores as a function of the relative dehydration parameter $x=\frac{N(0)-N(\infty)}{N(0)}$. The experimental conditions correspond to $\mathrm{x}=0.65, \mathrm{SP}=0.35, \mathrm{~N}(\infty)=0.35 \mathrm{~N}(0)$ for pumping rate $134 P a$ $s^{-1}$. For a pumping rate of $560 P a s^{-1}, \mathrm{X}=1, \mathrm{SP}=0, \mathrm{~N}(\infty)=0$ 

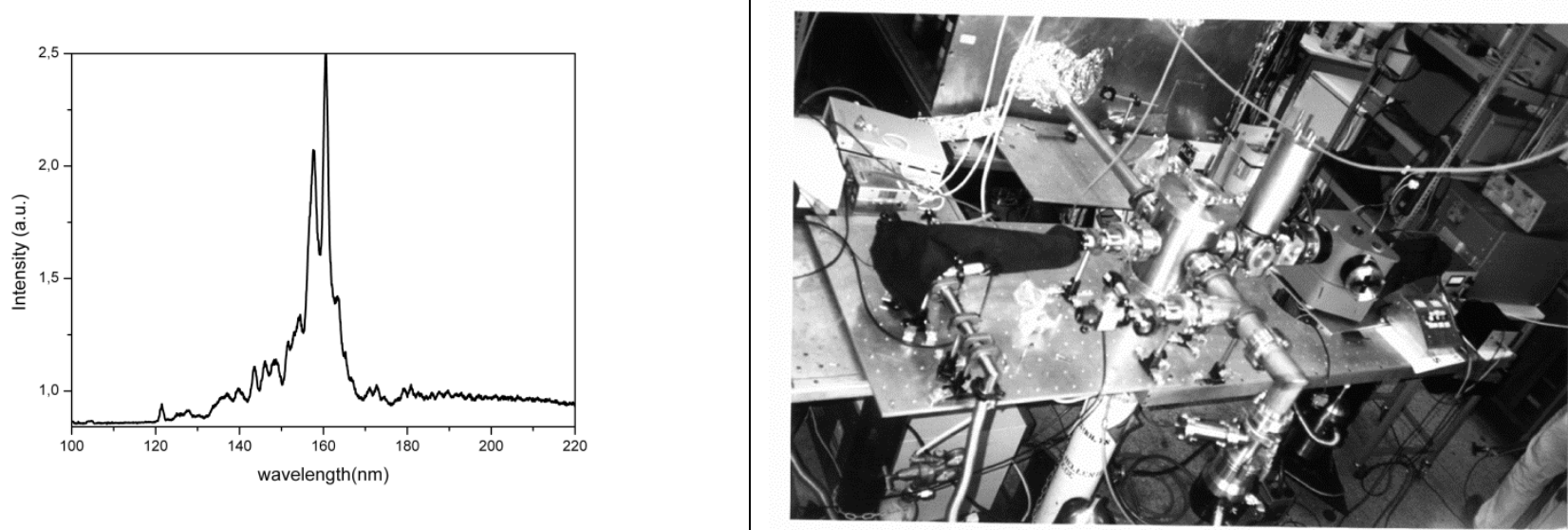

Fig.1

Fig.2

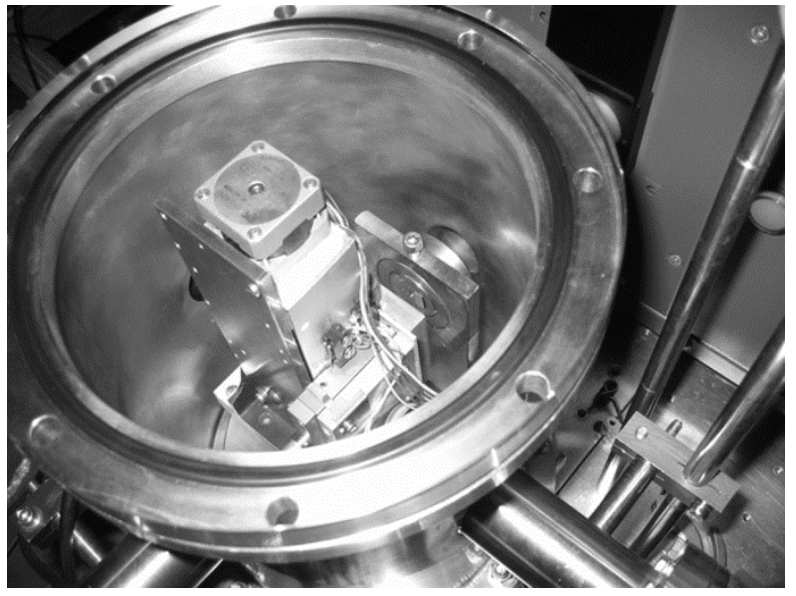

Fig. 3

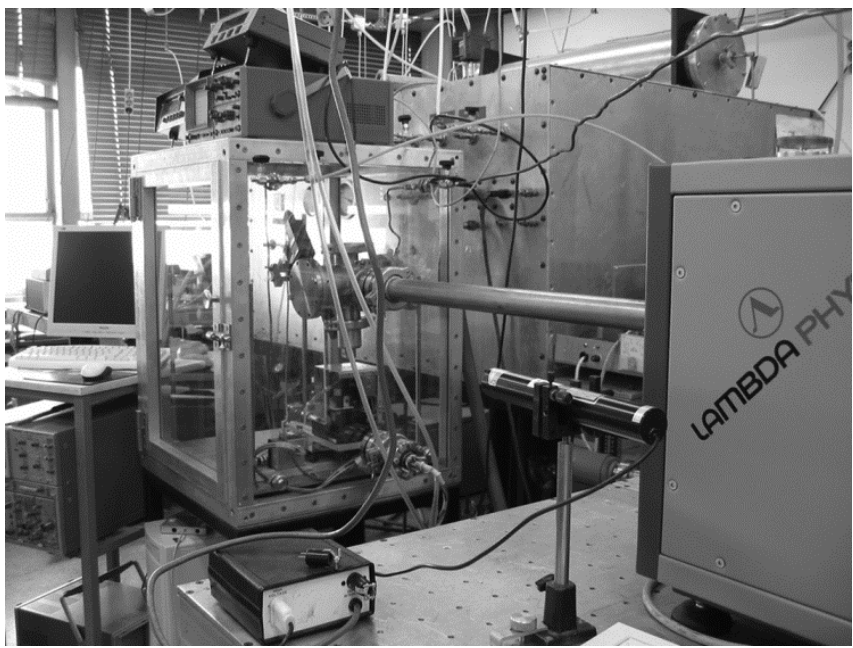

Fig.4
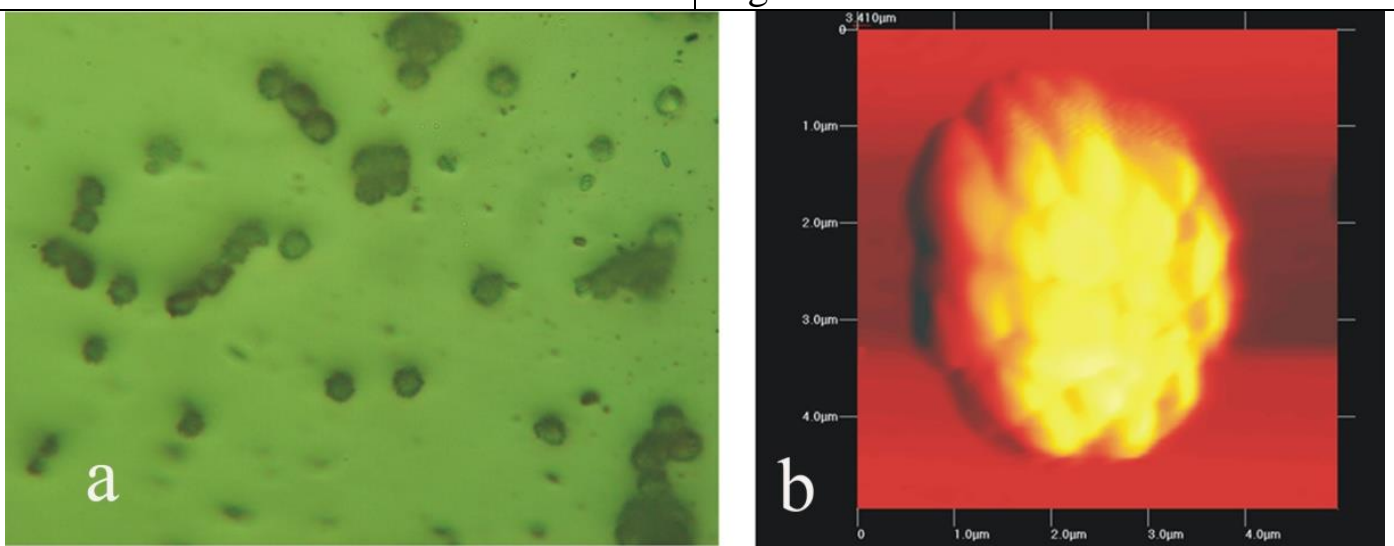

Fig.5 


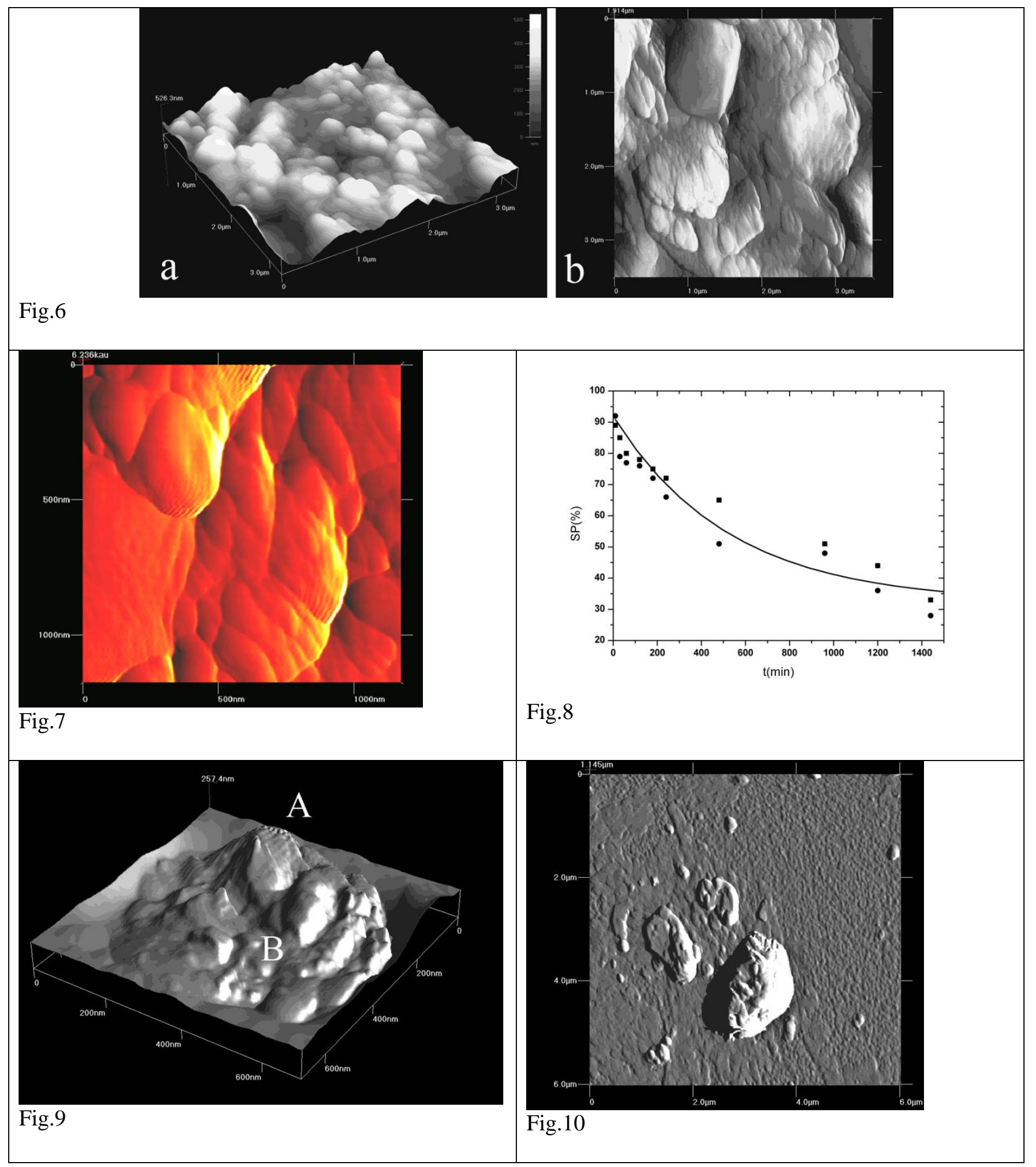




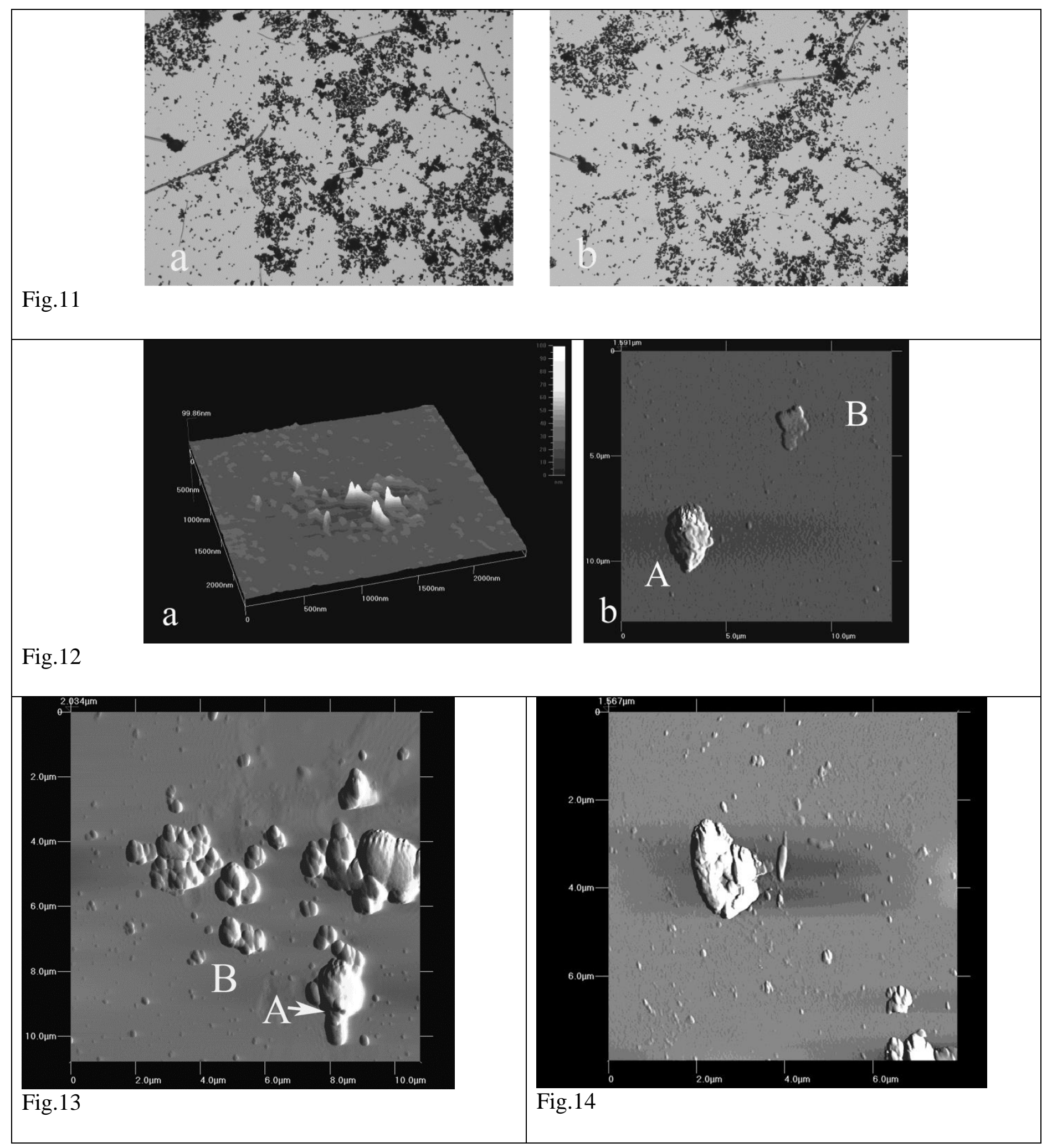




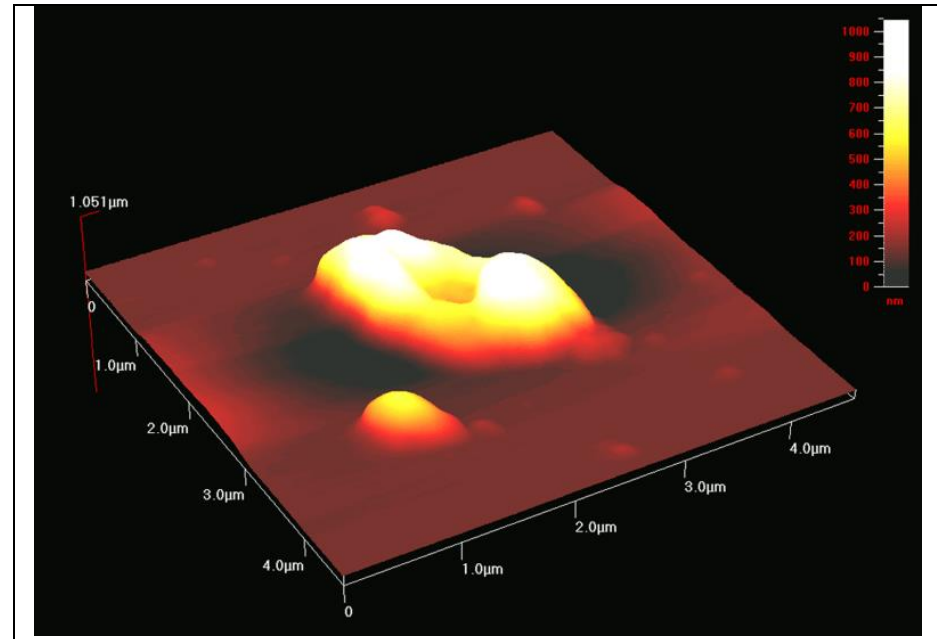

Fig.15

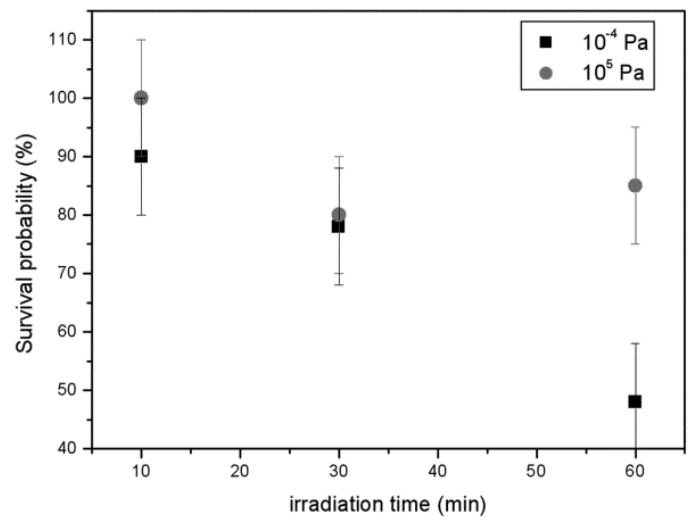

Fig. 17

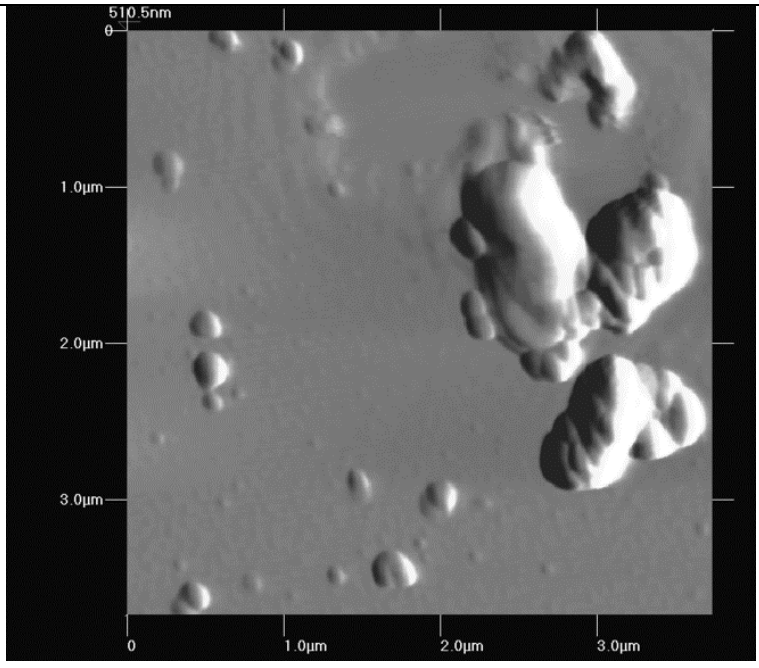

Fig. 16

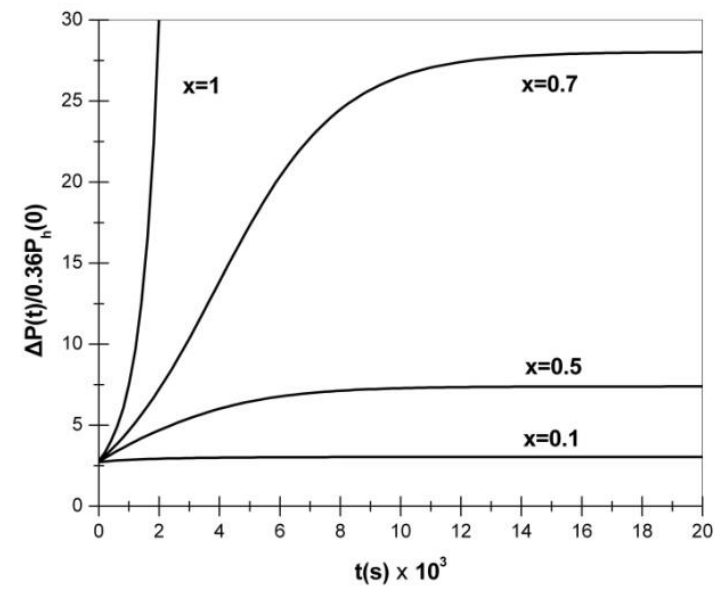

Fig.18 


\section{Tables}

\begin{tabular}{|c|c|c|c|c|}
\hline $\begin{array}{l}\text { Exposure } \\
\text { time (sec) } \\
x_{10}^{2}\end{array}$ & $\begin{array}{l}\text { SP }(\%) \\
10^{-4} \mathrm{~Pa}, \\
298 \mathrm{~K}\end{array}$ & $\begin{array}{l}\text { SP }(\%) \\
10^{-4} \mathrm{~Pa} \\
10 K\end{array}$ & $\begin{array}{l}\text { SP }(\%) \\
10^{-4} \mathrm{~Pa}, 298 \mathrm{~K} \\
F_{S}=1.26 \mathrm{~mW} \mathrm{~m}^{-2} \\
\left(10^{15} \text { photons } \mathrm{m}^{-2} \mathrm{~s}^{-1}\right)\end{array}$ & $\begin{array}{l}\mathrm{SP}(\%) \\
10^{-4} \mathrm{~Pa}, 10 \mathrm{~K} \\
\mathrm{~F}_{\mathrm{L}}=1.26 \mathrm{mWm}^{-2} \\
\left(10^{15} \text { photons } \mathrm{m}^{-2} \mathrm{~s}^{-1}\right)\end{array}$ \\
\hline 6 & 89 & - & 92 & - \\
\hline 18 & 85 & - & 79 & - \\
\hline 36 & 80 & - & 77 & - \\
\hline 72 & 78 & - & 76 & - \\
\hline 108 & 75 & - & 72 & - \\
\hline 144 & 72 & - & 66 & - \\
\hline 288 & 65 & 73 & 51 & 68 \\
\hline 576 & 51 & 64 & 48 & 63 \\
\hline 720 & 44 & 58 & 36 & 64 \\
\hline 864 & 33 & 52 & 28 & 58 \\
\hline 3456 & 31 & 54 & 30 & 61 \\
\hline
\end{tabular}

Table 1. Survival probability (SP) of Aspergillus terreus spores exposed at different temperature and low intensity VUV photons at $10^{-4} \mathrm{~Pa}$. The main damage on spores is from the vacuum.

\begin{tabular}{lllllll}
\hline $\begin{array}{l}\text { Irradiation } \\
\text { time }(\mathbf{s e c})\end{array}$ & $\begin{array}{l}\text { Number of } \\
\text { laser pulses }\end{array}$ & $\begin{array}{l}\mathbf{S P}(\%) \\
\mathbf{1 0} \mathbf{1 0}^{\mathbf{2}} \mathbf{P a}\end{array}$ & $\begin{array}{l}\text { Growth } \\
\text { rate } \\
\text { colony } \\
(\mathbf{m m} / \text { day })\end{array}$ & $\begin{array}{l}\mathbf{F}_{\mathbf{L}} \\
\left(\mathbf{p h o t o n s} \mathbf{~ m}^{-2}\right)\end{array}$ & $\begin{array}{l}\mathbf{F}_{\mathbf{S}} \\
\left(\text { photons } \mathbf{~ m}^{-2}\right)\end{array}$ & $\begin{array}{l}\mathbf{S P}(\%) \\
\mathbf{1 0}^{\mathbf{5}} \mathbf{P a}\end{array}$ \\
\hline $10^{-11}$ & 1 & 100 & 30 & $5.9 \times 10^{19}$ & - & \\
6 & 9 & 100 & 3.1 & $5.3 \times 10^{23}$ & $6 \times 10^{17}$ & 100 \\
18 & 27000 & 80 & 3.0 & $1.59 \times 10^{24}$ & $1.8 \times 10^{18}$ & 100 \\
36 & 54000 & 85 & 2.0 & $3.18 \times 10^{24}$ & $3.6 \times 10^{18}$ & 98 \\
864 & - & - & - & - & $8.6 \times 10^{19}$ & 96 \\
\hline
\end{tabular}

Table 2. Survival probability (SP) of Aspergillus terreus spores at different laser photon fluence $\mathrm{F}_{\mathrm{L}}$ at $10^{5} \mathrm{~Pa}$ and $298 \mathrm{~K}$. The $\mathrm{SP}$ of spores irradiated with the hydrogen source at different photon fluence $F_{S}$ is included in the table for comparison.

The survival probability of spores is between $100-80 \%$ for the photon fluence between $10^{19}-10^{24}$ photons $m^{-2}$. 


\begin{tabular}{|c|c|c|c|c|c|c|}
\hline $\begin{array}{l}\text { Irradiation } \\
\text { time (sec) } \\
\times 10^{2}\end{array}$ & $\begin{array}{l}\text { Number of } \\
\text { laser pulses }\end{array}$ & $\begin{array}{l}\text { SP }(\%) \\
10^{-4} \mathrm{~Pa} \\
\text { (Laser) }\end{array}$ & $\begin{array}{l}\mathbf{F}_{\mathbf{L}} \\
\left(\text { photons } \mathbf{m}^{-2}\right)\end{array}$ & 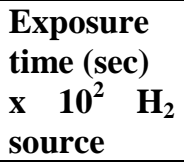 & $\begin{array}{l}\mathbf{F}_{S} \\
\left(\text { photons } \mathrm{m}^{-2}\right)\end{array}$ & $\begin{array}{l}\text { SP (\%) } \\
10^{-4} \text { Pa }\end{array}$ \\
\hline 6 & 9000 & 82 & $5.3 \times 10^{23}$ & 6 & $6 \times 10^{17}$ & 92 \\
\hline 18 & 27000 & 64 & $1.59 \times 10^{24}$ & 18 & $1.8 \times 10^{18}$ & 79 \\
\hline 36 & 54000 & 31 & $3.18 \times 10^{24}$ & 36 & $3.6 \times 10^{18}$ & 77 \\
\hline 864 & - & - & - & 864 & $8.6 \times 10^{19}$ & 28 \\
\hline 3456 & - & - & - & 3456 & $3.4 \times 10^{20}$ & 30 \\
\hline
\end{tabular}

Table 3. Survival probability (SP) of Aspergillus terreus spores irradiated with different laser photon fluence $\mathrm{F}_{\mathrm{L}}$ at $10^{-4} \mathrm{~Pa}$ and $298 \mathrm{~K}$. The SP of spores irradiated with the hydrogen source at different photon fluence $F_{S}$ is shown for comparison. 
Intensity of $\mathrm{H}_{2}$ source

Emission wavelength of $\mathrm{H}_{2}$ source

Peak Wavelength $\mathrm{H}_{2}$ source

Laser wavelength

Laser pulse duration at FWHM

Laser photon energy per pulse

Laser Photon fluence per pulse

Laser Intensity

Initial vacuum pressure at $\mathrm{t}=0$

Final pressure or rotary pump

Final pressure (turbomolecular)

Pumping speed at $t=0$

Pumping speed at $t \rightarrow \infty$

Pumping speed rate

Characteristic dimensionless

constant of vacuum system

Rate of change of pumping speed

Biological rate constant

Average size of spores

Young modulus

Hydration pressure

Hydration length

Water surface density $(\mathrm{t}=0)$

Water surface density $t \rightarrow \infty$

Dehydration parameter

\begin{tabular}{|l|l}
$\mathrm{F}_{\mathrm{S}}$ & $10^{15} \mathrm{photons}^{2} \mathrm{~s}^{-1}$ \\
$\lambda_{\mathrm{e}}$ & $110-180 \mathrm{~nm}$ \\
$\lambda_{\mathrm{p}}$ & $\sim 157 \mathrm{~nm}$ \\
$\lambda_{\mathrm{L}}$ & $157 \mathrm{~nm}$ \\
$\tau$ & $15 \mathrm{~ns}$ \\
$\mathrm{~F}_{\mathrm{LE}}$ & $75 \mathrm{~J} \mathrm{~m}^{-2}$ \\
$\mathrm{~F}_{\mathrm{L}}$ & $5.9 \times 10^{19}$ photons pulse $^{-1} \mathrm{~m}^{-2}$ \\
$\mathrm{I}_{\mathrm{L}}$ & $3.9 \times 10^{27}$ photons pulse $^{-1} \mathrm{~m}^{-2}$ \\
& $\mathrm{~s}^{-1}$ \\
$\mathrm{P}_{\mathrm{e}}(0)$ & $10^{5} \mathrm{~Pa}$ \\
$\mathrm{P}_{\mathrm{e}}(\infty)$ & $1 \mathrm{~Pa}$ \\
$\mathrm{P}_{\mathrm{et}}(\infty)$ & $10^{-4} \mathrm{~Pa}$ \\
$\beta(0)$ & $1.1 \times 10^{-3} \mathrm{~m}^{3} \mathrm{~s}^{-1}$ \\
$\beta(\infty)$ & $0.57 \times 10^{-3} \mathrm{~m}^{3} \mathrm{~s}^{-1}$ \\
$\mathrm{~B}_{1}$ & $0.016 \mathrm{~s}^{-1}$ \\
$\mathrm{~B}_{2}$ & 0.94 \\
& \\
$\alpha$ & $(0.011 \pm 0.008) \mathrm{s}^{-1}$ \\
$\gamma$ & $(1.90 \pm 0.49) \times 10^{-3} \mathrm{~s}^{-1}$ \\
$\mathrm{r}$ & $\sim 3 \mu \mathrm{m}$ \\
$\mathrm{E}$ & $6.6-22 \mathrm{GPa}$ \\
$\mathrm{P}_{\mathrm{h}}(\infty)$ & $\sim(0.1-2.5) \mathrm{E}$ \\
$\mathrm{D}$ & $2 \times 10^{-10} \mathrm{~m}$ \\
$\mathrm{~N}(\mathrm{D})$ & $8.36 \times 10^{15} \mathrm{~m}^{-2}$ \\
$\mathrm{~N}(\infty)$ & $0.34 \mathrm{~N}(\mathrm{D})$ \\
$\mathrm{X}$ & $0.67 \pm 0.04$ \\
&
\end{tabular}

Table 4. Experimental parameters. 